OPEN ACCESS

Edited by:

Alessandro Scarso,

Università Ca' Foscari, Italy

Reviewed by:

Eric Monflier,

Artois University, France

Dong-Sheng Guo,

Nankai University, China

*Correspondence:

Margherita De Rosa

maderosa@unisa.it

Specialty section:

This article was submitted to

Supramolecular Chemistry,

a section of the journal

Frontiers in Chemistry

Received: 10 January 2018

Accepted: 12 March 2018

Published: 03 April 2018

Citation:

De Rosa M, La Manna P, Talotta C

Soriente A, Gaeta C and Neri P (2018)

Supramolecular Organocatalysis in Water Mediated by Macrocyclic Compounds. Front. Chem. 6:84. doi: 10.3389/fchem.2018.00084

\section{Supramolecular Organocatalysis in Water Mediated by Macrocyclic Compounds}

\author{
Margherita De Rosa * Pellegrino La Manna, Carmen Talotta, Annunziata Soriente, \\ Carmine Gaeta and Placido Neri
}

Dipartimento di Chimica e Biologia "Zambelli", Università degli Studi di Salerno, Salerno, Italy

In the last decades many efforts have been devoted to design supramolecular organocatalysts able to work in water as the reaction medium. The use of water as solvent provides promising benefits with respect to environmental impact. In this context, macrocyclic compounds played a role of primary importance thanks to their ease of synthesis and their molecular recognition abilities toward the reactants. The aim of this review is to give an overview of the recent advances in the field of supramolecular organocatalysis in water, focusing the attention on calixarene and cyclodextrins derivatives. Calixarenes and cyclodextrins, thanks to their hydrophobic cavities, are able to host selectively the substrates isolating they from the reaction environment. In addition, the synthetic versatilities of these macrocycles permits to introduce useful functional groups in close proximity of the hydrophobic binding sites. Regarding the cyclodextrins (CDs), we have here reviewed the their most recent uses as organocatalysts for the synthesis of heterocyclic compounds, in multi-component reactions and in carbon-carbon bond forming reactions. Examples have been reported in which CD catalysts are able to drive the regiochemistry of common organic reactions. In addition, cyclodextrins bearing catalytically active chiral groups, have shown excellent enantioselectivity in the catalysis of organic reactions. Recently reported results have shown that calixarene derivatives are able to accelerate organic reaction under "on-water" conditions with a significant selectivity toward the reactants. Under "on-water conditions" the hydrophobic effect, induced by insoluble calixarene derivatives, forces the reactants and the catalyst to aggregate and thus accelerating the reaction between them thanks to an amplification of weak secondary interactions. Regarding the use of water-soluble calixarene organocatalysts, we have here reviewed their role in the acceleration of common organic reactions.

Keywords: supramolecular organocatalysis, water, hydrophobic effect, molecular recognition, calixarenes, cyclodextrins

\section{INTRODUCTION}

In the last decades, a growing interest has been devoted to the development of new synthetic methodologies with the aim to emulate the high performance of biological processes (Dong et al., 2012; Raynal et al., 2014; Borsato and Scarso, 2016; Deraedt and Astruc, 2016; Kuah et al., 2016). In natural biosynthetic processes, the enzymatic machines work in water where they reach amazing 
levels of efficiency, selectivity, and specificity (Copeland, 2002; Bugg, 2012). Taking inspiration from the biological systems, several scientists have devoted many efforts to the design of artificial systems with the aim of mimicking the levels of performance of natural enzymes. At this regards, a particular emphasis has been placed to the study of organic reactions in water as the medium (Kobayashi and Li, 2012). Water, as a solvent, possesses many desirable characteristics for a reaction medium, because it is not only environmentally benign, but with its high heat capacity, high polarity, large cohesive energy, and hydrogen bonding abilities may have a significant impact on the reaction course influencing reaction rate and selectivity. In a pioneering work, Breslow highlighted the attractiveness of water as reaction medium and as reaction promoter of a DielsAlder cycloaddition (Rideout and Breslow, 1980; Breslow, 1991; Simon and Li, 2012). Successively, Sharpless introduced for the first time the expression "on-water conditions" to indicate the rate acceleration observed in organic reactions when insoluble reactants are vigorously stirred in a water suspension (Narayan et al., 2005; Pirrung, 2006). As shown by Schreiner (Kleiner and Schreiner, 2006) and Rueping (Rueping and Theissmann, 2010), the polar nature and the hydrogen bonding abilities of water do not limit its use as a solvent in organocatalyzed reactions where the substrates are activated by covalent or secondary weakinteractions (Sakthivel et al., 2001; Pirrung and Sarma, 2004; Pirrung, 2006; Raj and Singh, 2009; Butler and Coyne, 2010; Mase and Barbas, 2010; Giacalone and Gruttadauria, 2013; De Rosa et al., 2016, 2017b; Jimeno, 2016). On the other hand, in fact, the natural enzymes stay and work in aqueous environment, where the enzyme-substrate complexes survive to the presence of water. The knowledge of the mechanisms underlying enzymatic catalysis has been an important source of inspiration for the design of supramolecular biomimetic organocatalysts (Steed and Atwood, 2009; Kirby and Hollfelder, 2010; Marchetti and Levine, 2011; Raynal et al., 2014). Thus, in the last years different types of supramolecular organocatalysts have been designed which have shown excellent catalytic efficiency and amazing regio-and stereoselectivity (Zhang and Tiefenbacher, 2015; Zhang et al., 2017; La Manna et al., 2018). The supramolecular organocatalysts so far known are constituted by macrocyclic scaffolds in which an internal cavity binds the substrate through secondary interactions with functional groups present in close proximity of the cavity. Inspired by the natural systems, in the macrocyclic-based supramolecular organocatalysts the internal cavity is able to accommodate the reactants isolating them from the bulk medium and provides a confined reaction environment. In this way, an enhancement of the local concentration of the reactants is obtained, thus promoting the reaction by proximity effects. In addition, the substrate selectivity is dictated by the size and shape of the internal cavity. More recently, many efforts have also been devoted to the design of self-assembled nanocapsules able to host different guests and to promote reactions inside their cavities. (Dong et al., 2011, 2012; Longstreet and McQuade, 2013; La Sorella et al., 2015; Deraedt and Astruc, 2016; Kuah et al., 2016).

In this review, we highlight some recent examples of macrocyclic-based supramolecular organocatalysts (Figure 1) able to catalyze organic reactions using water as a reaction medium. In details, we will focus our attention on examples concerning the use of calixarene and cyclodextrin macrocycles as scaffolds for supramolecular catalysts. Calixarenes and cyclodextrins are among the most popular macrocycles in supramolecular chemistry where they have shown amazing abilities in different fields. Calixarene and cyclodextrin macrocycles possess many desirable features for the design of supramolecular catalysts: (a) a hydrophobic internal cavity able to host the substrates in a selective way; (b) an excellent synthetic versatility which permits the introduction of functional groups in close proximity of their cavities. Thanks to these characteristics, calixarene, and cyclodextrin derivatives have found many applications in the field of supramolecular organocatalysis and we will highlight the most recent ones in this review.

In Tables 1, 2 the most recent catalytic performances of cyclodextrins and calixarenes evaluated in this work are summarized.

\section{REACTION ORGANOCATALYZED BY CAVITY-CONTAINING MACROCYCLIC SCAFFOLDS}

\section{Cyclodextrins}

Cyclodextrin macrocycles (CD) are a family of naturally occurring molecules formed by $\alpha$-1,4-linked D-glucose units associated head-to-tail to form a truncated conical structure. They have a hydrophobic inner core, made by glycosidic oxygen atoms and hydrocarbon $\mathrm{CH}$-groups, which is surrounded by an outer hydrophilic surface formed by polar hydroxyl groups. The presence of hydroxyl groups ensures not only their water solubility but also the possibility of a direct interactions with substrates or the introduction of other functional groups. The number of the glucopyranoside units in the macrocycle modulates the cavity size being the most common cyclodextrins composed of $6(\alpha-C D), 7(\beta-C D)$, and $8(\gamma-C D)$ units (Figure 1).

The first evidences for the potential use of CDs in catalysis as enzyme models can be traced back to Bender's studies in the hydrolysis of phenyl acetate in the presence of CD where a remarkable substrate specificity was found (Van Etten et al., $1967 a, b)$. Since then, a large number of works have been reported regarding the role of native and modified CDs in different types of reactions (Macaev and Boldescu, 2015; Srivastava et al., 2016; Bai et al., 2017). Their catalysis may be classified generally in two types: (a) covalent when an CD -reactant intermediate is formed through a covalent bond which then evolves in products, (b) non-covalent when the interactions between CD and reactants are non-covalent and CD hydrophobic cavity offers a microenvironment where the reaction takes place (Breslow and Dong, 1998; Takahashi, 1998; Komiyama and Monflier, 2006). Interestingly, complex of the CDs with transition metal have been used as water-soluble organometallic catalysts in several reactions, in addition CDs based material have been used as unconventional reaction media such as supramolecular hydrogels or low melting mixtures (LMMs) (Hapiot et al., 2014, 2017). Furthermore, when metals are not involved in 

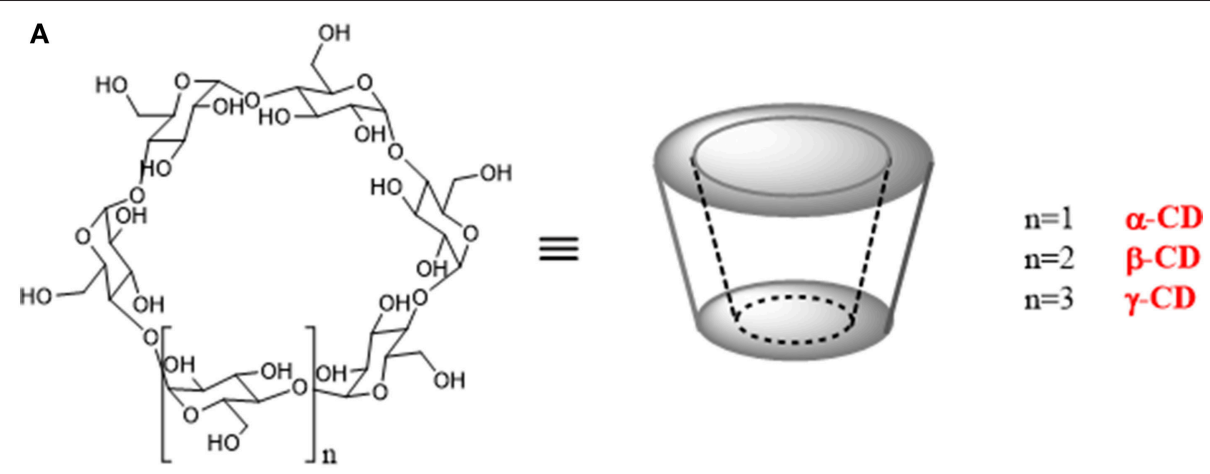

B

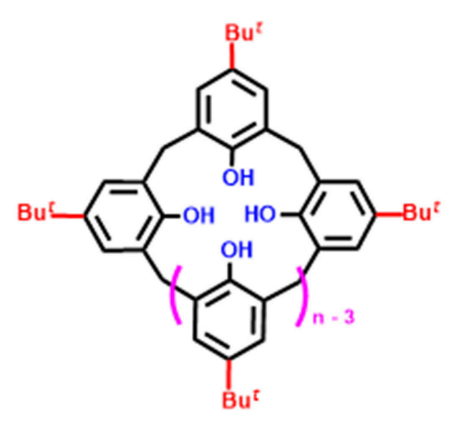

1
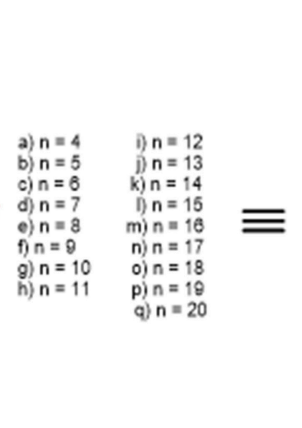

exo or upper rim

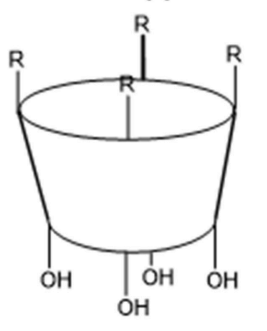

endo or lower rim

FIGURE 1 | Chemical structure of macrocyclic cavity-containing scaffolds: (A) cyclodextrins (CD); (B) calix[n]arenes.

TABLE 1 | Summary of the catalytic performance of cyclodextrin macrocycles evaluated in this review.

\begin{tabular}{|c|c|c|}
\hline Organocatalyst & Application & References \\
\hline \multirow[t]{6}{*}{ Native $\beta-C D$} & Synthesis of tryptanthrin analogs & Kumar et al., 2011 \\
\hline & $\begin{array}{l}\text { Synthesis of 2,3-dihydroquinazolin- } 4(1 \mathrm{H}) \text {-one derivatives via three-component } \\
\text { reaction }\end{array}$ & Ramesh et al., 2012 \\
\hline & $\mathrm{C}-\mathrm{H}$ bond functionalization of 2-alkyl-azaarenes with diones & Kumar and Shukla, 2014 \\
\hline & $\begin{array}{l}\text { Deprotection of hydroxyl group accompanied by cyclization or ring opening of } \\
\text { chalcone epoxides }\end{array}$ & Kumar et al., 2015 \\
\hline & Synthesis of polysubstituted pyrroles via one-pot four component procedure & Konkala et al., 2016 \\
\hline & 1,3-dipolar cycloaddition & Floresta et al., 2017 \\
\hline Native $\beta$-CD /IBX & $\begin{array}{l}\text { Deprotection with oxidative cleavage of chalcone epoxides and oxidative } \\
\text { dehydrogenation of alcohols }\end{array}$ & Kumar and Ahmed, 2016 \\
\hline \multicolumn{3}{|l|}{ MODIFIED CYCLODEXTRINS } \\
\hline Proline-cyclodextrin coniugates & Aldol reaction & Doyagüez and Fernández-Mayoralas, 2012 \\
\hline Proline-cyclodextrin coniugates & Aldol reaction & Liu and Zhang, 2015 \\
\hline$\beta$-cylodextrins peramino & One-pot synthesis of enantiomerically enriched quinolone derivatives & Kanagaraj and Pitchumani, 2013 \\
\hline Sulfonated- $\beta$-cyclodextrin & Electrophilic substitution reaction of indoles with isatins & Tayade et al., 2015 \\
\hline Partially methylated $\beta$-CDs (RAME- $\beta-C D)$ & Paal-Knorr condensation between 1,4-diketones and primary amines & Menuel et al., 2014 Akelis et al., 2016 \\
\hline
\end{tabular}

the CD catalytic activity, the catalysis falls in the field of the supramolecular organocatalysis (Bogliotti and Dalko, 2007; Marinescu and Bols, 2010), and interesting works have been reported in recent years.

\section{Native Cyclodextrins Promoted Reactions}

In 2011, Kumar et al. reported an efficient and eco-friendly procedure for the synthesis of tryptanthrin analogs 4 mediated by non-modified $\beta$-CD (Kumar et al., 2011). Tryptanthrin analogs are an interesting class of heterocycle compounds characterized by a broad spectrum of biologic activities against different pathogens such as antibacterial, antifungal, antitubercular activities and, furthermore a potential anticancer agent against some human cancer cell-lines (Dzierzbicka et al., 2003; MartinezViturro and Dominguez, 2007; Kshirsagar, 2015). The reaction did not proceed without the assistance of $\mathrm{CD}$ and, between the 
TABLE 2 | Summary of the catalytic performance of calixarene macrocycles evaluated in this review.

\begin{tabular}{|c|c|c|}
\hline Organocatalyst & Application & References \\
\hline \multirow[t]{7}{*}{ Calix[4]arene with a chiral proline moiety at the upper or lower rim } & Aldol reaction & Li et al., 2009 \\
\hline & & Li et al., 2010 \\
\hline & & Eymur et al., 2014 \\
\hline & & Uyanik et al., 2014 \\
\hline & & Aktas et al., 2016 \\
\hline & & Sahin et al., 2016 \\
\hline & & Li et al., 2017 \\
\hline Calix[4]arene with imidazole moieties at the lower rim & $\begin{array}{l}\text { Aromatic nucleophilic substitution reaction } \\
\text { Benzyl nucleophilic substitution }\end{array}$ & Yang et al., 2012 \\
\hline Calix[n]-arenes with quaternary ammonium salts at the upper rim & One-pot Mannich reaction & Sayin and Yilmaz, 2014 \\
\hline p-Sulfonic acid calixarenes & Synthesis of 2,3-dihydroquinazolyn-4(1H)-ones & Rahaman et al., 2015 \\
\hline Calix[6]arene sulfonic acid derivatives & Michael addition between indoles and $\alpha, \beta$-unsaturated ketones & Xie et al., 2013 \\
\hline Thioureido calix[n]arenes & Vinylogous Mukaiyama Aldol reaction & De Rosa et al., 2016 \\
\hline Tetraminocalix[4]arene & Vinylogous Mukaiyama Aldol reaction & De Rosa et al., 2017b \\
\hline
\end{tabular}

most common cyclodextrins, only $\beta$-CD proved to be the most efficient catalyst. These results pointed out the dual role played by the CD not only as catalyst but also as nanoreactor; the $\beta$ $\mathrm{CD}$ had the right cavity size to accommodate both reactants and thus induce the reactive events. The mechanistic hypothesis for the reaction proposed the imprisonment of the reactants in the CD cavity, the activation of carbonyl group at C-4 position of isatoic anhydride 1 through hydrogen bonding interaction with the hydroxyl groups of the $\mathrm{CD}$, attack of the isatin 2 leading to cleavage of anhydride ring and formation of an intermediate 3 which, in turn, transforms into the final product 4. (Figure 2) ${ }^{1} \mathrm{H}-\mathrm{NMR}$ studies confirmed the formation of an inclusion complex between isatoic anhydride 1 and $\beta-C D$. The substrate scope proved general with different substituted isatins as well as substituted isatoic anhydrides affording the product in good to high yields not in a long time (5-9 h).

In 2012, Ramesh and coworkers reported an interesting example of a one-pot protocol mediated by CDs in water. (Figure 3) For the first time a cyclodextrin promoted via threecomponent reaction the synthesis of 2,3-dihydroquinazolin4(1H)-one derivatives 8 and 9, molecules exhibiting several biological and pharmacological activities. The reaction between aniline 7, aldehyde $\mathbf{6}$ and isatoic anhydride 5 afforded the products in good yields and in short reaction times with only $10 \% \mathrm{~mol} \beta$-CD. The recovery and reuse of the CD with little loss of efficiency, simple work-up and the use of water as reaction medium made it a powerful alternative method. (Ramesh et al., 2012).

In 2014, Kumar and Shukla used cyclodextrins as catalysts to perform a $\mathrm{C}\left(\mathrm{sp}^{3}\right)-\mathrm{H}$ functionalization of 2-alkyl-azaarenes 10 with a series of homocyclic and heterocyclic diones 11 in water. (Figure 4) The reaction was interesting because it was a simple, green, and valid route to form carbon-carbon and carbon-heteroatom bonds, generally formed in the presence of transition metals. Different CDs were evaluated, $\beta$-CD turned out to be the best catalyst affording the product 12 in high yield in only $4 \mathrm{~h}$ at $80^{\circ} \mathrm{C}$. The catalytic role of $\mathrm{CD}$ was pointed out by the absence of reactivity without CD. Studies by ${ }^{1} \mathrm{H}-\mathrm{NMR}$ spectra underlined up field shift of $\beta$-CD protons when mixed with the reactants thus confirming the formation of inclusion complexes. Under the optimal reaction conditions, the reaction was general for various isatins and 2-methylquinoline, different heterocyclic and homocyclic diones, regardless of the substitution pattern. Interestingly, the catalyst was recyclable up to 5 times without significant losses of efficiency (Kumar and Shukla, 2014).

Interesting and promising application of CD was proposed by Kumar et al. for the deprotection of hydroxyl groups. (Figure 5) They reported that THP/MOM/Ac/Ts ethers 13 could be deprotected under mild and eco-friendly conditions in the presence of $\beta-C D$ in water. Particularly, the combined use of water and microwave irradiations greatly reduced the reaction times to minutes without loss of efficiency (Figure 5A). It is noteworthy that, under the reaction conditions, they observed not only deprotection of hydroxyl group but also a concomitant regioselective cyclization of chalcone epoxides 17 to 2-hydroxyindanones 18 and 2 -aminochalcones to azaflavanones, respectively. Different evidence was recorded for the chalcones, the procedure stopped at the deprotection without evidence of cyclization. With $2^{\prime}$-aminochalcones the reaction efficiency depended on the nature of substituents. If the substituent on $\mathrm{Ar}^{2}$ ring of aminochalcones was electrondonating group, the cyclization was favored giving the product in higher yield, while an electron-withdrawing group slowed the cyclization and so decreased the reaction efficiency. In the reaction mechanism proposed by the authors, the $C D$ played a dual role: (a) activation of the THP ether and epoxide by $\mathrm{H}$-bond interactions and, at the same time (b) formation of inclusion complex controlled the regioselective ring opening of epoxide at $\beta$-carbon. (Kumar et al., 2015). Later, the authors extended this procedure (Kumar and Ahmed, 2016). The reaction of deprotection was carried out using $\beta-\mathrm{CD}$ and oiodoxybenzoic acid (IBX) in water. Under these conditions a onepot deprotection with oxidative cleavage of chalcone epoxides 23 and oxidative dehydrogenation of alcohols 21 was observed. The reaction afforded $\beta$-hydroxy-1, 2-diketones $24, \alpha, \beta$-unsaturated ketones 22 and 1,2,3-triketones 25 in moderate to high yields 
<smiles>[R]c1cc2[nH]c(=O)oc(=O)c2cc1[R]</smiles><smiles>[R9]c1ccc2c(c1)C(=O)C(=O)N2</smiles>

2

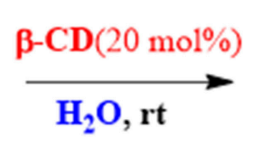

$\mathrm{R}_{1}=\mathrm{H}, \mathrm{OCH}_{3}$

$\mathrm{R}_{2}=\mathrm{H}, \mathrm{Br}, \mathrm{NO}_{2}, \mathrm{NH}_{2}, \mathrm{OCH}_{3}, \mathrm{Cl}$

$\mathrm{R}_{3}=\mathrm{H}, \mathrm{OCH}_{3}, \mathrm{Br}, \mathrm{CH}_{3}, \mathrm{Cl}, \mathrm{NO}_{2}, \mathrm{~F}, \mathrm{I}$,<smiles>[R]c1ccc2c(c1)C(=O)n1c-2nc2cc([R])c([R])cc2c1=O</smiles>

yield: $79-90 \%$
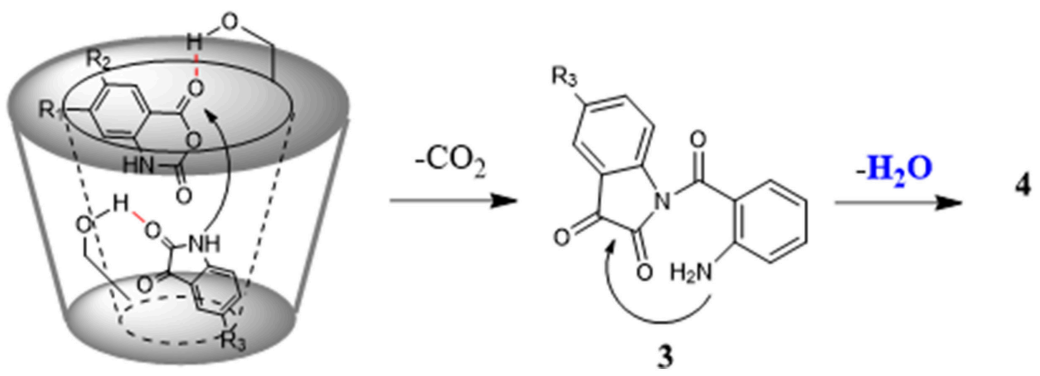

3

FIGURE 2 | CD mediated synthesis of tryptanthrin analogs in water.

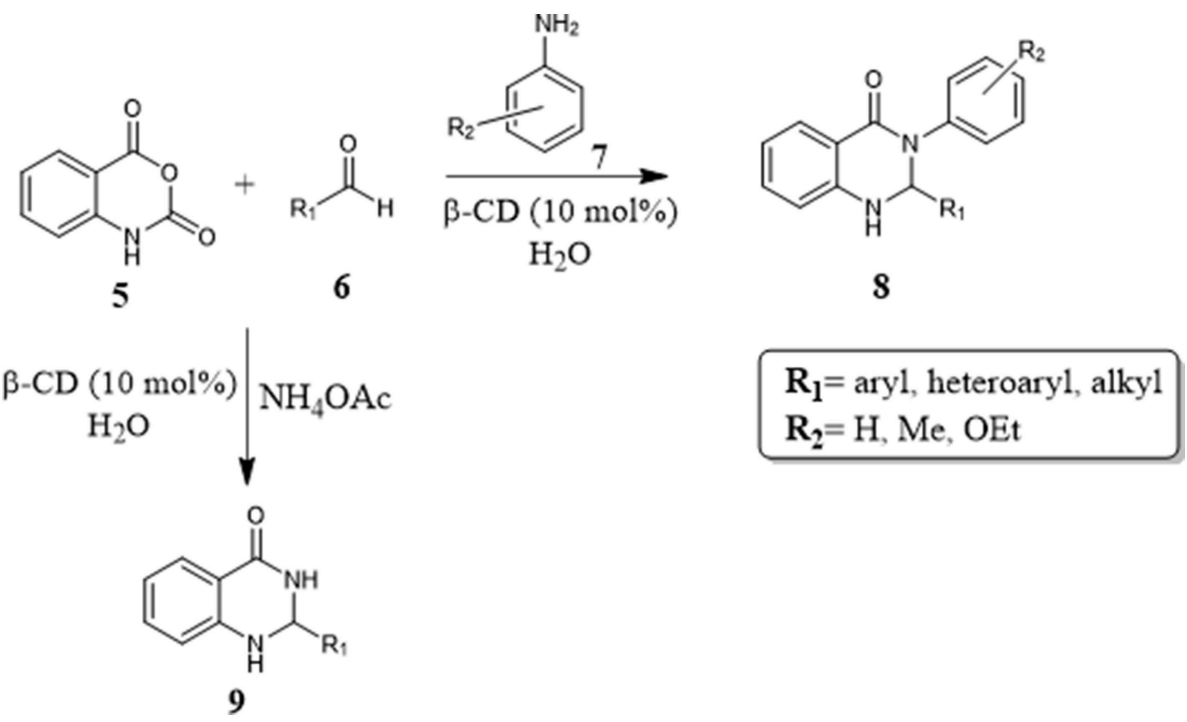

FIGURE 3 | CD promoted one-pot synthesis of 2,3-dihydroquinazolin-4(1H)-one derivative.

requiring low reaction time. Once again, the dual role played by $\beta$-CD was evident. In the THP ether deprotection and concurrent oxidative cleavage of chalcone epoxide, $\beta$-CD not only activated the ether and epoxide through hydrogen bonding interactions, but also controlled the regioselective opening of epoxide forming inclusion complex (Figure 5).

One-pot four-component procedure promoted by $\mathrm{CD}$ for the preparation of polysubstituted pyrroles $\mathbf{3 0}$ was reported for the first time by Konkala et al. (2016) The synthesis of substituted pyrroles is complicated mainly by the occurrence of undesired polymerization reactions or lack selectivity, this protocol provided efficient and selective. The poor results obtained by using sodium dodecyl sulfate (SDS) or PEG400 , pointed out that $\mathrm{CD}$ did not act as a transfer phase catalyst and so the high reaction performance in its presence could be attributed to the formation of inclusion complexes within its hydrophobic cavity thereby facilitating the sequence of the reaction. NMR studies confirmed the incorporation 


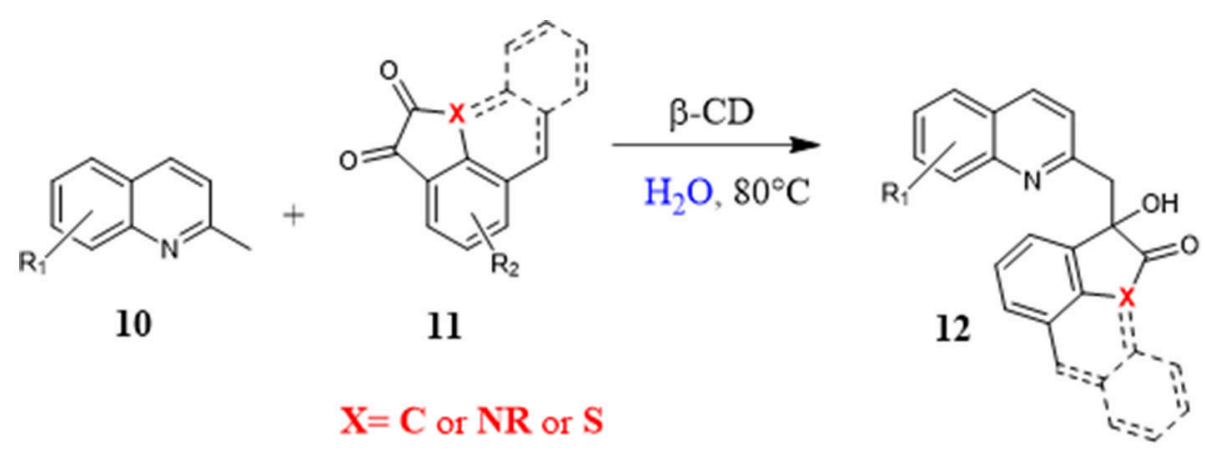

yield: $81-91 \%$

FIGURE 4 | $\beta$-CD mediated $C\left(\mathrm{sp}^{3}\right)$-H functionalization of 2-alkyl-azaarenes with diones in water.

A Kumar, S. 2015

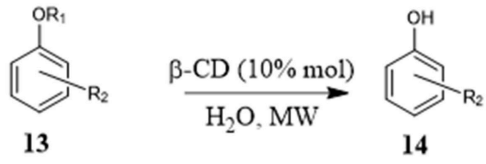

$\mathrm{R}_{1}=$ THP, MOM, Ac, Ts $\quad 61-99 \%$<smiles>[R6]Oc1ccc(C(=O)C2OC2c2ccc([R6])cc2)cc1</smiles>

$\mathrm{R}_{1}=\mathrm{THP}, \mathrm{MOM}, \mathrm{Ac}, \mathrm{Ts}$ $\mathrm{R}_{4}=\mathrm{Cl}, \mathrm{Br}, \mathrm{OMe}, \mathrm{F}$<smiles>[R6]c1ccc(C2c3cc(O)ccc3C(=O)C2O)cc1</smiles>
$95-99 \%$

B Kumar, S. 2016
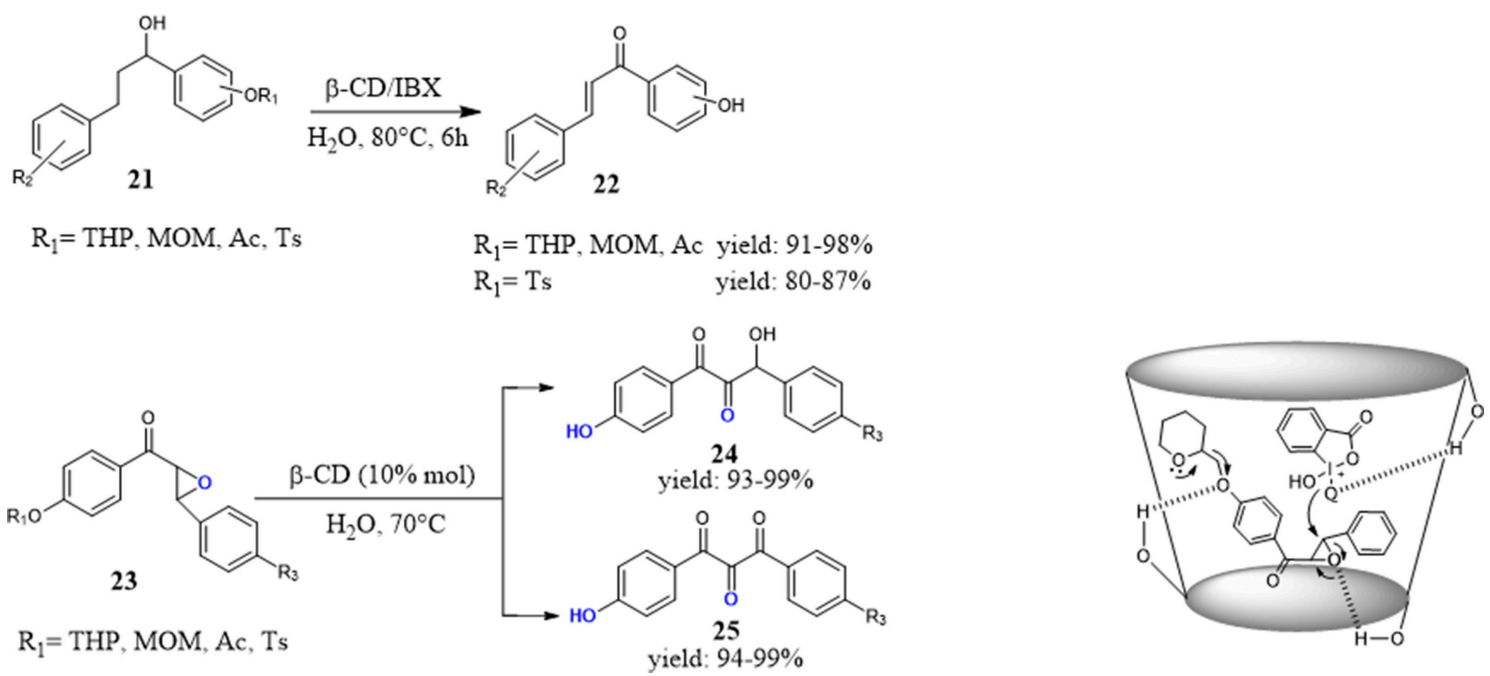

FIGURE 5 | $\beta$-CD mediated deprotection of hydroxyl groups in water: (A) deprotection reaction and one-pot deprotection with subsequent cyclization of chalcone epoxides; (B) one-pot deprotection and concurrent oxidation reaction.

of the aldehyde 26 and the formation of $\beta$-CD-aldehyde inclusion complex. Once activated, the aldehyde reacted with nitromethane 29 to form nitrostyrene which, in turn, reacted with in situ generated $\beta$-ketoenamine and, a subsequent oxidative aromatization led to the final product. (Figure 6) The scope of the reaction is broad with respect to the nature of the aldehyde and amine affording many substituted pyrroles in good to high yields.

Recently, Floresta et al. employed $\gamma$-cyclodextrin as a catalyst in the 1,3-dipolar cycloaddition between different nitrones 31 and styrenes or cynnamates $\mathbf{3 2}$ to give substituted isoxazolidines 33 and 34 in high yields and good to high diastereomeric 


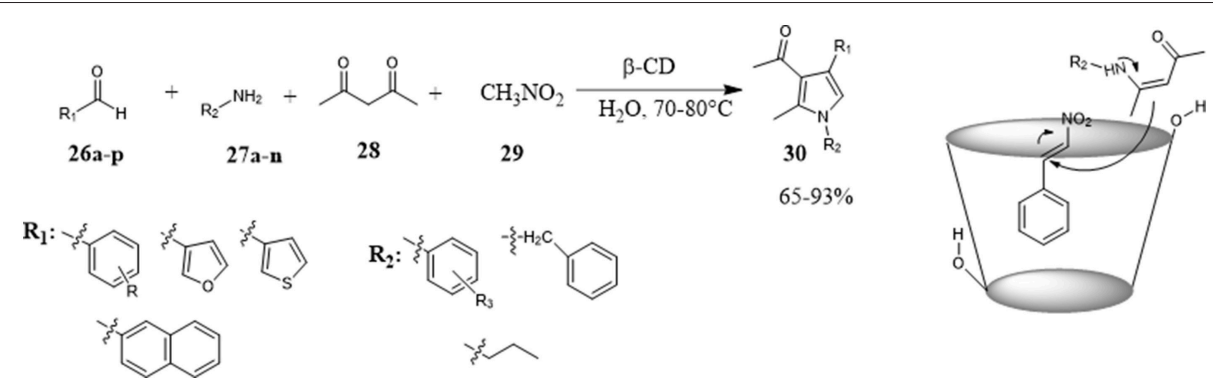

FIGURE 6 | One-pot four-component procedure for the synthesis of substituted pyrroles in water promoted by $\beta$-CD.

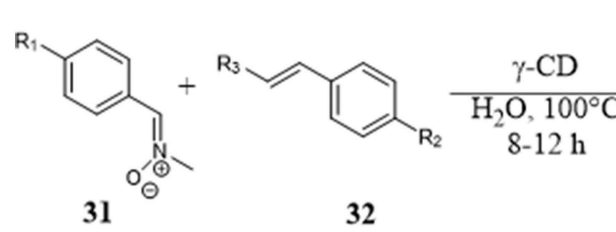

$\mathbf{R}_{1}: \mathrm{H}, \mathrm{NO}_{2}$ $\mathbf{R}_{\mathbf{2}}: \mathrm{H}, \mathrm{COOEt}$ $\mathbf{R}_{\mathbf{3}}: \mathrm{H}, \mathrm{NO}_{2}, \mathrm{OMe}$

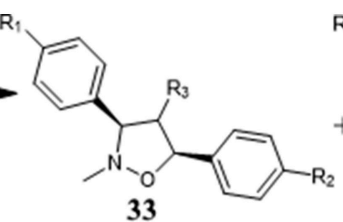

33

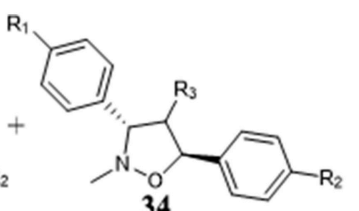

34

12 examples

yield: $75-85 \%$

cis/trans ratio: $2.7 / 1-25 / 1$

inclusion hetero complex for catalytic event

FIGURE 7 | $\gamma$-Cyclodextrin catalyzes 1, 3-dipolar cycloaddition between different nitrones and styrenes to afford substituted isoxazolidines.

excesses. The role of CD was ascribed to the formation of hostguest complexes between $\mathrm{CD}$ and the reactants mediated by noncovalent interactions (Figure 7). When the reactants were included together into the hydrophobic CD cavity, the catalytic event took place. In fact, the reaction did not proceed with $\alpha$ - and $\beta$-CD, their cavity size were too small to simultaneously accommodate both reactants. Evidences from HR FT-ICR MALDI-MS and NMR studies supported these conclusions. The recycle of catalyst without loss of activity, the use of water as reaction medium and high reaction efficiency made the protocol competitive with those carried out in organic solvent. Furthermore, in silico studies were used to rationalize the reaction stereoselectivity outcome and to improve it by the choice of proper substrates able to interact with the cyclodextrin through hydrogen bond interactions. In fact, the calculations supported an inclusion mode with the insertion of phenyl ring of styrene 32 within the cavity pointing to the down rim and with the phenyl of nitrone $\mathbf{3 1}$ protruding out the cavity at the height of secondary $\mathrm{OH}$ groups in the upper rim (Floresta et al., 2017).

\section{Modified Cyclodextrins Promoted Reactions}

Many modified cyclodextrins have been prepared through selective conversion of the hydroxyl groups to other functionalities with the aim to modify and improve their catalytic abilities. The introduction of one or more reactive binding sites in precise positions can offer multiple molecular recognition sites and allow a more effective and selective catalysis (Hattori and Ikeda, 2006).

In the field of supramolecular organocatalysis, the rationale of this approach is based on the possibility of combining the catalytic properties of an organocatalyst placed in an appropriate position on the CD scaffold and suitable for the target reaction and the ability of cyclodextrins to form inclusion complexes.

In 2012, Doyagüez and Fernández-Mayoralas reported the use of cyclodextrins functionalized with proline as efficient supramolecular organocatalysts for aldol reactions in water (Figure 8A). Several coniugates of L-proline and $\beta$-CD 38 were prepared changing the nature of the linker between proline and $\beta-C D$ and tested as catalysts for the aldol reaction between p-nitrobenzaldehyde 35 and different ketones 36 and 37. A dependency on the nature of the linker was highlighted and the best results were obtained with more flexible succinamyl moiety. Studies were performed to understand the role played by $\beta$-CD. The reaction carried out with the proline arm alone, depleted of CD scaffold, did not take place even after prolonged reaction times, and the poor conversion observed by adding 
A Doyaguez, E.G. and Fernandez-Mayoralas, A.

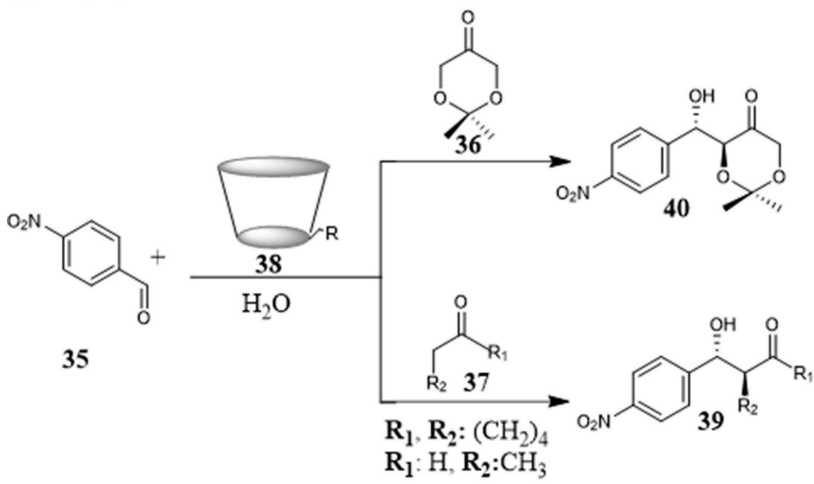

B Liu, $K$. and Zhang, $G$.
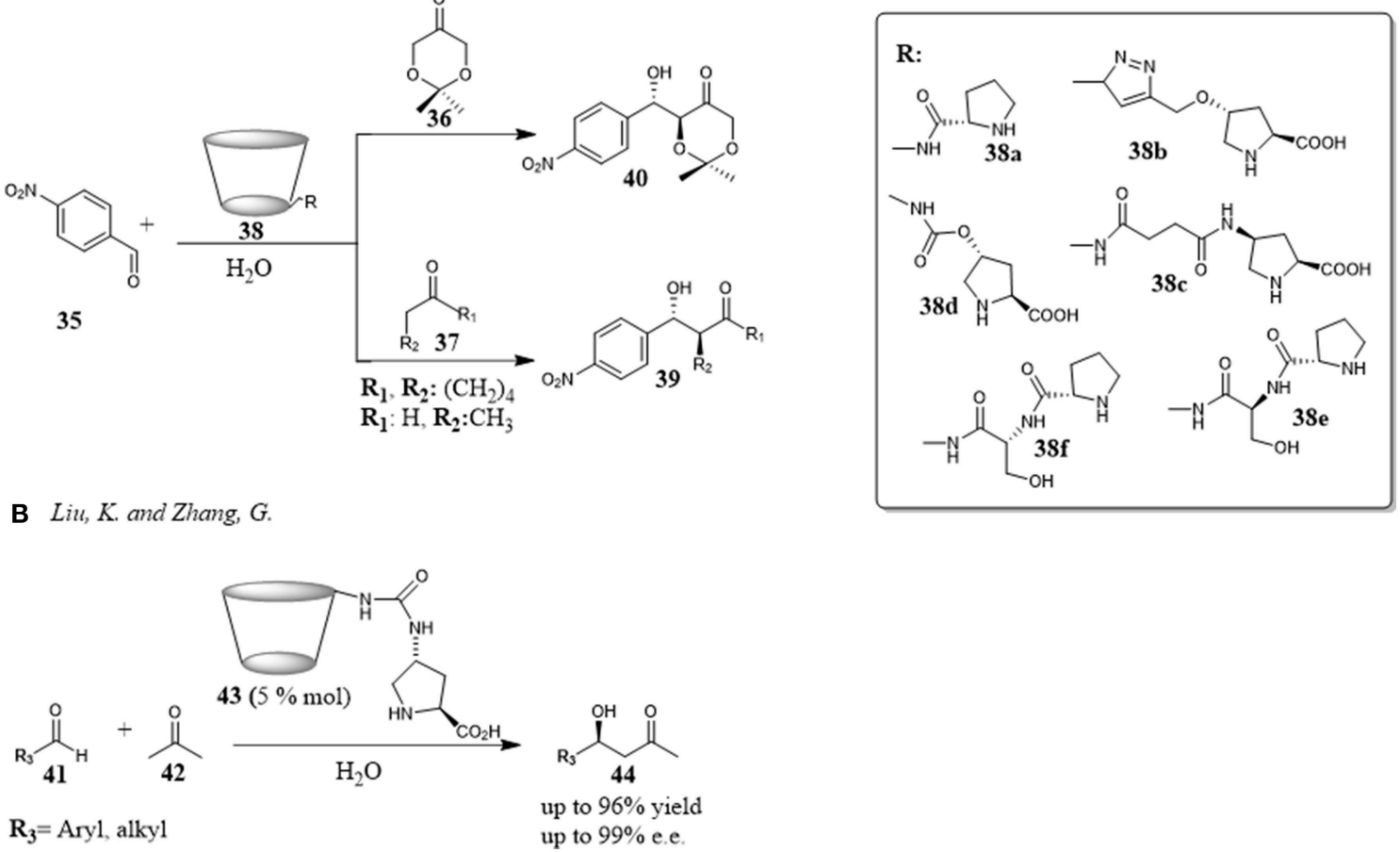

FIGURE 8 | Proline-cyclodextrin coniugates catalyze the aldol reaction: (A) Aldol reaction between p-nitrobenzaldehyde and different ketones in the presence of CD-derivatives 38; (B) Aldol reaction between different aldehydes and acetone in the presence of CD-derivative 43.

$\beta$-CD to the reaction suggested a role of $\beta$-CD in dissolving the reactants. The reaction efficiency decreased by adding sodium 2-naphthalenesulfonate, a known high affinity guest for $\beta$-CD (Inoue et al., 1993), pointing out the role of hydrophobic cavity by forming inclusion complexes with the aldehyde. Unfortunately, although the reaction efficiency ranged from moderate to high yields, the enantioselectivity was poor (Doyagüez and FernándezMayoralas, 2012).

Higher enantioselectivities were obtained by Liu and Zhang for the aldol reaction between different aldehydes 41 and acetone 42 in the presence of a $\beta$-cyclodextrin 43 with a proline linked via a urea functional unit (Figure 8B). Aromatic and aliphatic aldehydes reacted with acetone in moderate to good yields and with good to high enantioselectivities. The reaction efficiency showed a substrate dependence that the authors attributed to the different binding abilities with the interior cavity of $\beta$-CD. In fact, the drop in the reaction enantioselectivity obtained in the order para-, meta- and orto-substituted benzaldehydes was consistent with the decrease of binding constants between the substituted aromatic aldehydes and $\beta$-CD. Moreover, an interesting advantage of the procedure was the recycle of the catalyst. After the product isolation with an organic solvent, the catalyst being soluble in water remained in the aqueous phase which could be used as reaction medium for another reaction. This process could be done several times without loss of the reactivity and enantioselectivity. (Liu and Zhang, 2015).

In 2013, $\beta$-cylodextrins peramino (per-6-ABCDs) functionalized on primary face were reported for the first time in an efficient one-pot procedure for the synthesis of enantiomerically enriched quinolone derivatives 47, privileged building blocks useful to access a wide array of biologically active compounds (Kanagaraj and Pitchumani, 2013). Per6-ABCDs behaved simultaneously as a supramolecular host and a chiral multifunctional base catalyst giving the reaction adducts with high yields and enantiomeric excesses. The persubstitution of the $\mathrm{CD}$ with amino groups was demonstrated to be necessary for the reaction outcome. When the reaction was performed with native $\beta-\mathrm{CD}$ or $\beta$-CD and external base or per-amino- $\beta$-CD hydrochloride, the reaction efficiency fell down significantly in terms of conversion and enantioselectivity. The substrate scope of the reaction was explored using various aryl and heteroaryl substituted aldehydes 45 . The reaction worked well showing independent on the electronic nature of aryl substituents, but their position on the ring and size exerted significant influence on the enantioselectivity suggesting the importance of a tight fitting of guests within the chiral cavity. The mechanism proposed involved in the first step the inclusion of $o$-aminoacetophenone 46 and aldehyde 45 within $\mathrm{CD}$ cavity. The primary amino groups of $\mathrm{CD}$ acted both as a base abstracting a proton by the acetyl group of $o$-aminoacetophenone $\mathbf{4 5}$ and hydrogen-bond donor toward the carbonyl group of aldehyde 46 (Figure 9A). The condensation between the activated substrates yielded the corresponding chalcone which subsequently underwent isomerization via aza-Michael reaction and then tautomerization to give the target compounds. The inclusion of $o$-aminoacetophenone 45 inside 
A Kanagaraj, K. and Pitchumani, K, 2013<smiles>[R]C(=O)[C-]1C=CC(N)=C(C(C)=O)C1</smiles>

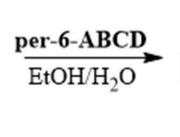<smiles>O=C1CC(P)Nc2ccccc21</smiles><smiles>CCCCC[Te]</smiles>

R: aryl, heteroaryl, alkyl 20 examples yield: $>99 \%$ e.e.: $>99 \%$
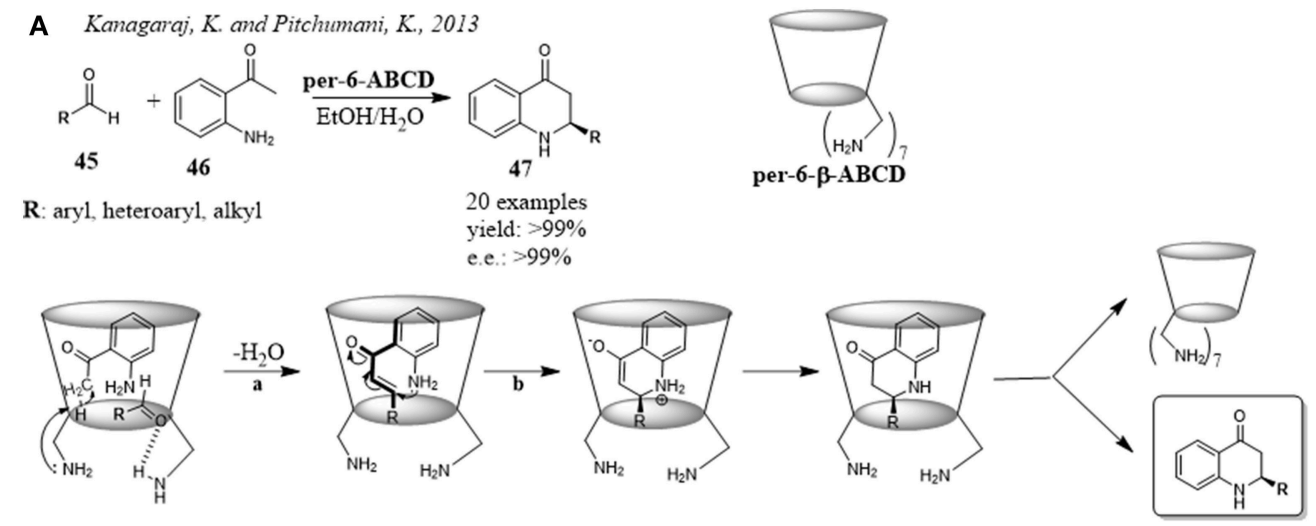

B Tayade, Y. et al., 2015
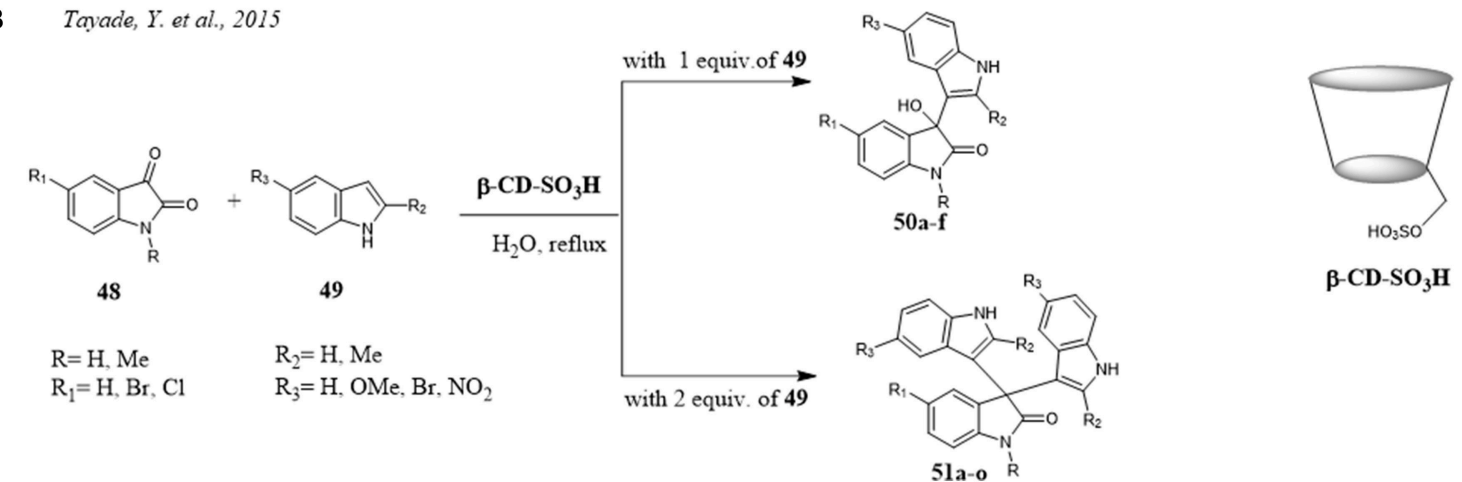

B-CD-SO $3 \mathrm{H}$

FIGURE 9 | Synthesis of heterocycles promoted by CDs: (A) Peramino-CDs promote the synthesis of quinolone scaffolds; (B) Efficient synthesis of indole derivatives catalyzed by a sulfonated- $\beta$-cyclodextrin.

the CD cavity and its activation at $\mathrm{Si}$ face by amino groups of CD drove the stereochemical outcome of the aza-Michael addition. Excellent enantiomeric excesses were obtained with a host to guest ratio of 1:1. Molecular modeling studies, NMR and ESI-MS data provided further support to the proposed mechanism.

Another efficient application of modified CDs in the synthesis of heterocyclic scaffolds was reported by Tayade et al. A sulfonated- $\beta$-cyclodextrin was able to promote the reaction between different indoles 49 and isatins 48 to give the corresponding products $\mathbf{5 0}$ or $\mathbf{5 1}$ in good to excellent yields in very short reaction times (Figure 9B). The results obtained showed that the electronic effects of the substituents influenced only slightly the reaction outcome. The accelerated rate and high efficiency were ascribed to greater solubility of sulfonated- $\beta$ $\mathrm{CD}$ than native $\beta$-CD in water and more effective formation of inclusion complexes with isatins. Reaction optimization studies highlighted that $10 \mathrm{~mol} \%$ of sulfonated- $\beta$-cyclodextrin and reflux temperature were the best conditions for this reaction resulting in excellent yields and extremely short reaction times (from $5 \mathrm{~h}$ at room temperature to $5 \mathrm{~min}$ at reflux). Additional advantage of the reaction was that the catalyst could be recovered and reused for three catalytic cycles without significant loss in catalytic activity (Tayade et al., 2015).

Amazing results were obtained using cyclodextrins in the Paal-Knorr condensation between 1,4-diketones and primary amines for the synthesis of pyrroles. (Menuel et al., 2014; Akelis et al., 2016) Partially methylated $\beta$-CDs (RAME- $\beta$-CD) have been used as mass transfer agents promoting the Paal-Knorr condensation of 1,4-diketones $\mathbf{5 3}$ and amines $\mathbf{5 2}$ for the synthesis of $\mathrm{N}$-substituted pyrroles $\mathbf{5 4}$ under mild reaction conditions (Figure 10A). The activity of RAME- $\beta$-CDs resulted better than their native analogs and the results were explained on the basis of their higher water solubility and surface activity. The reaction was explored with different ketones and aromatic and aliphatic amines. In all cases, the corresponding products were obtained in good yields. The proposed mechanism involved the inclusion of amine inside the CD cavity, and an interaction between the amine and an hydroxyl group of the $\mathrm{CD}$ which promoted pyrrole formation. Particularly, when the reaction was performed with aliphatic and aromatic diamines 55, the amount of amine used affected the selective formation of monopyrrole 56 or unsymmetrical bis-pyrrole derivatives 57 (Figure 10B).

\section{Calixarenes}

Calixarenes represent a fascinating class of macrocyclic compounds particularly investigated in supramolecular chemistry (Figure 1B). They are constituted by p-tertbutylphenol units bridged with methylene units. Calix $[n]$ arenes have the general structure reported in Figure 1 in which the number $n$ of phenolic units ranges from 4 to 20. However, the 
A<smiles>[R16][R16]#N</smiles>

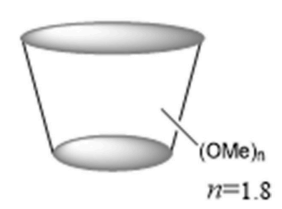

RAME$\beta-C D$
R:<smiles>C[As]1(C)CC=CC=C1I</smiles><smiles>[Y]c1ccc2ccccc2c1</smiles><smiles>[Y][Y]([H])([CH])CCO</smiles><smiles>C1CCC2CCCC2C1</smiles>
$n=1$ or 11

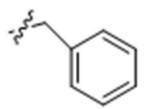<smiles>CC(C)(C)c1cccc2ccccc12</smiles>

B

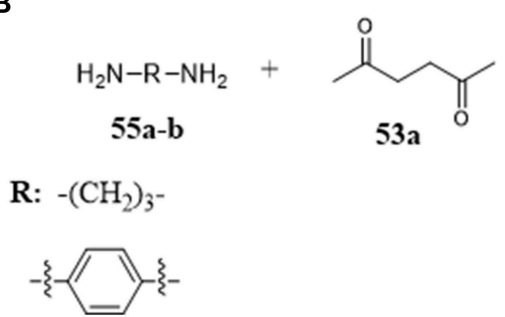

a: $\mathrm{R}_{1}=\mathrm{R}_{2}=\mathrm{CH}_{3}$

b: $\mathrm{R}_{1}=$

c: $R_{1}=R_{2}=$

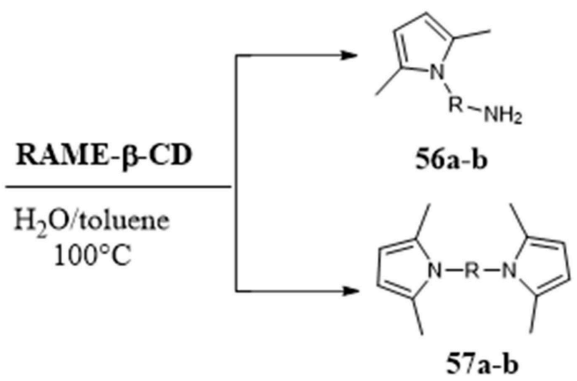

FIGURE 10 | Paal-Knorr pyrrole synthesis assisted by partially methyled $\beta$-cyclodextrins: (A) Paal-Knorr condensation of 1,4-diketones and amines; (B) Paal-Knorr condensation of 1,4-diketones and diamines.

most studied members are those constituted by 4-8 aromatic units. The name "calixarene" was introduced by C. D. Gutsche who was inspired by the similarity of the cone-conformation of calix[4]arene 1a with a greek vase (calix crater) (Gutache et al., 1975; Gutsche and Muthukrishnan, 1978). Subsequently, this name was also extended to the other calixarene homologs. Calixarenes show a central hydrophobic cavity of controllable size, in addition to a wide upper rim and a narrow lower rim. The synthetic and structural versatility of these macrocycles make them suitable for different applications, (Böhmer, 1995; Gaeta et al., 2002; De Rosa et al., 2015; Neri et al., 2016; Talotta et al., 2017) including molecular recognition and sensing (Guo et al., 2011, 2012, 2013; Gaeta et al., 2012; Guo and Liu, 2014; Sun et al., 2016; Talotta et al., 2016; Yeon et al., 2016; Zheng et al., 2018), self-assembly processes (Rebek, 2000; Rudkevic, 2001; DíazMoscoso et al., 2016), synthesis of interpenetrated architectures (Gaeta et al., 2013, 2016; Arduini et al., 2016; De Rosa et al., 2017c; La Manna et al., 2017; Talotta et al., 2018), and catalysis (Cacciapaglia and Mandolini, 2000; Li et al., 2011; Deraedt and Astruc, 2016; Stoikov et al., 2016; Yilmaz and Sayin, 2016).

Calix[4]arenes bearing a chiral proline moiety at upper or lower rim have been successfully used by some research groups as organocatalysts for the direct aldol reaction between cyclohexanone $\mathbf{5 9}$ and various aromatic aldehydes $\mathbf{5 8}$ in water. (Figure 11) The catalytic activity of these calixarene derivatives highlighted the key role of their hydrophobic cavities for the reaction outcome, considering the poor activity of proline alone as promoter of the direct aldol reaction in water. For all catalysts the observed results suggested a mechanism based on general enamine catalysis where the reaction was accelerated by the formation of a hydrophilic and hydrophobic region through hydrogen bonding interactions between the free- $\mathrm{OH}$ groups of interfacial water molecules and the $\mathrm{H}$-bond acceptor groups such as $\mathrm{OH}, \mathrm{NH}$, and $\mathrm{CO}$ groups of the calixarene scaffolds. Under optimal conditions, from good to high yields (>95\%), high enantioselectivities (>90\%) and from moderate to high diastereoselectivities (up to 65/35) were observed for all organocatalysts $60 \mathbf{a}-\mathbf{h}$. The recycle of the catalysts and their reuse without notable loss of activity and selectivity were characteristics common to all catalysts. Interestingly, catalyst 60e showed selectivity for cyclic ketones with different size thus providing further proof of the usefulness of its cavity as a selective nanoreactor for reactants (Li et al., 2009, 2010, 2017; Eymur et al., 2014; Uyanik et al., 2014; Aktas et al., 2016; Sahin et al., 2016).

A calix[4] arene bearing at lower rim imidazole moieties (64) was reported as an efficient phase-transfer catalyst for aromatic 


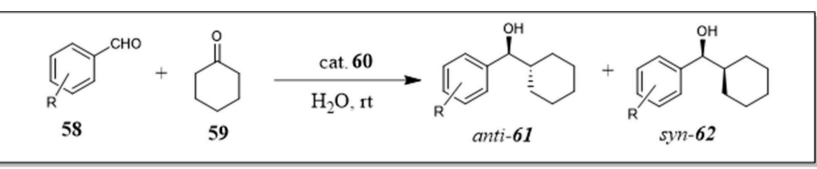

Lower rim functionalized calix[4]arenes

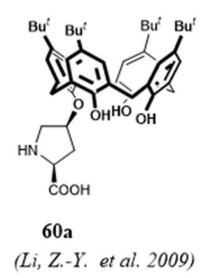

Upper rim functionalized calix[4]arenes

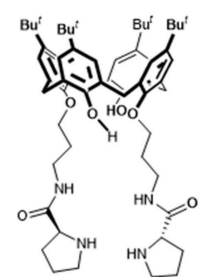

$60 \mathrm{~b}$

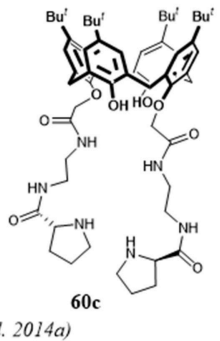

Yilmaz, M. et al. 2014a)

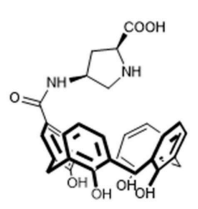

$60 \mathrm{e}$

(Li, Z.-Y. et al. 2017)

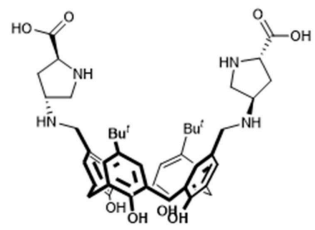

$60 \mathrm{f}$

(Yilmaz, M. et al. 2014b)

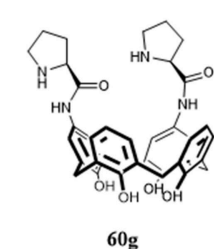

(Li, Z.-Y. et al. 2010)

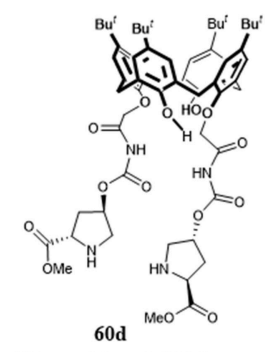

(Yilmaz, M. et al. 2016)

FIGURE 11 | Direct asymmetric aldol reaction catalyzed by calix[4]arene functionalized with a chiral proline.

nucleophilic substitution reaction and benzyl nucleophilic substitution (Figure 12A). The high catalytic abilities compared to classical ionic liquids suggested that not only the good solubility in water due to the presence of ions groups but also the combination with complexation abilities of its cavity played an important role for the catalysis: the aromatic substrate solubility in water was improved by inclusion in the calixarene cavity and by its structural conformation. The catalytic activity of the calixarene derivative was higher with the calixarene in more stable cone conformation (Yang et al., 2012).

In 2014, Sayin and Yilmaz investigated the feasibility to use calix[n]-arenes functionalized at the upper rim with quaternary ammonium salts 69 and 70 as catalyst for onepot Mannich reaction between benzaldehyde 66 , acetophenone 68 and aniline 67 in water. They found that the calixarene catalysts gave $\beta$-aminocarbonyl compounds $\mathbf{7 1}$ in high yields and very short reaction times, even with small amount of catalyst. (Figure 12B) Studies on the effect of cavity were carried out highlighting its involvement in the catalysis. In the presence of tetrabutylammonium bromide (TBAB) as competitive guest for the cavity, no conversion to reaction products was observed, even after prolonged reaction times, thus suggesting that the reaction occurred inside the cavity. Furthermore, comparing the results obtained with calix[4]- and calix[6] arene, it was highlighted that the calix[6]arene with a larger cavity size worked better than the other one in terms of yields and reaction times. Therefore, it could be concluded that the reaction was triggered by the host-guest complexation of benzaldehyde with calixarene, and the furoyl-piperazinium groups at the upper rim interacted with aniline and acetophenone by weak non-covalent interactions to bring closer to the benzaldehyde (Sayin and Yilmaz, 2014).

In 2015, Rahman et al. used p-sulfonic acid calixarenes 74 and 75 as organocatalysts for the synthesis of 2,3dihydroquinazolyn-4(1H)-ones 76 in water (Figure 12C). The reaction of cyclocondensation between anthranilamide 72 and different carbonyl compounds $\mathbf{7 3}$ afforded the target compounds in high yields under mild reaction conditions. The reaction performed with p-hydroxy benzenesulfonic acid ( $\mathrm{p}$-HAS) as catalyst, resulted less efficient than the reaction with calixarene derivatives $\mathbf{7 4}$ underlining the role of calixarene framework combined with its ability to activate aldehyde via $\mathrm{H}$-bonding interaction with the sulphonic groups on the reaction. The general scope, the scale-up of the reaction to gram-scale, easy work-up, low amount of catalyst, mild reaction condition, and short reaction time are considerable advantages of this protocol (Rahaman et al., 2015).

Another example of calixarene sulfonic acid derivatives as efficient organocatalysts has been described by Xie et al. Alkylation of indoles 77 with $\alpha, \beta$-unsaturated ketones 78 by means of Michael addition was promoted by water-soluble calix[6] arene sulfonic acids under microwave irradiation in water (Figure 12D). Calix[6] arene sulfonic acids 79 acted as inverse phase transfer catalysts. Particularly, calixarene 79d bearing pendant aliphatic chains and thus offering the possibility to form micelles in water, proved to be the optimal catalyst. The scope of the reaction was broad with respect to different indoles 77 and $\alpha, \beta$-unsaturated ketones 78, low amount of catalyst $(5 \mathrm{~mol} \%)$ are able to promote the reaction affording 
A<smiles>O=[N+]([O-])c1ccc(Cl)cc1</smiles>

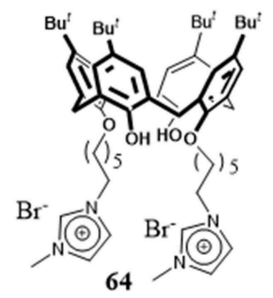

B<smiles>CC(C)C(=O)c1ccccc1C(=O)Oc1cccc(C(=O)CC(Nc2ccccc2)c2ccccc2)c1</smiles>

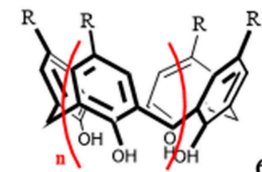

69: $\mathrm{n}=1$ 66 67 68 71

C
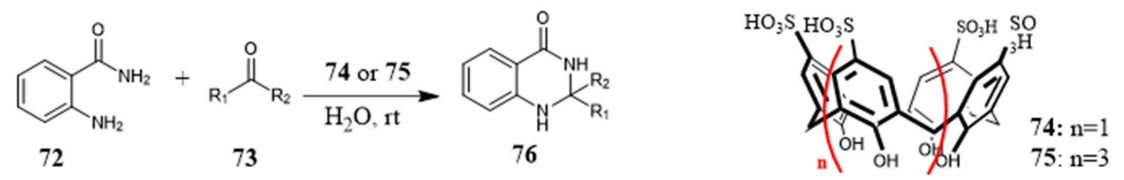

$\mathrm{R}_{1}=$ Aryl, heteroaryl, alkyl $\mathrm{R}_{2}=\mathrm{H}, \mathrm{CH}_{3}$

D<smiles></smiles>
77 $\mathrm{R}_{1}=\mathrm{H}, \mathrm{Me}, \mathrm{OMe}, \mathrm{NO}_{2} \quad \mathrm{R}_{3}=\mathrm{Me}$, Aryl, Heteroaryl $\mathrm{R}_{2}=\mathrm{H}$, Aryl, Alkyl<smiles></smiles>

so

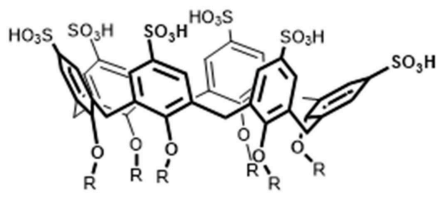

$79 \mathrm{a}: \mathrm{R}=\mathrm{H}$

79c: $\mathrm{R}=n-\mathrm{C}_{4} \mathrm{H}_{9}$

79b: $\mathrm{R}=\mathrm{Me}$

79d: $\mathrm{R}={ }_{n}-\mathrm{C}_{8} \mathrm{H}_{17}$

FIGURE 12 | Water-soluble calixarenes as supramolecular organocatalysts in: (A) nucleophilic substitution reaction; (B) Mannich reaction; (C) cyclocondensation reaction; (D) Michael addition reaction.

the Michael adducts in good to high yields (Xie et al., 2013).

Recently, calix[n]arene scaffolds adorned with a supramolecularly interacting group such as thiourea moiety have been used as organocatalysts for Vinylogous Mukaiyama Aldol reaction (VMAR) between 2-(trimethylsilyloxy)furan 82 and $\alpha$-ketoesters 81 under "on-water" conditions (Figure 13A). The reaction is a useful protocol to obtain functionalized $\gamma$-butenolides, which are valuable building blocks for many biologically active compounds and, recently interesting for the engineering of new crystalline assemblies (De Rosa et al., 2009, 2017a). It was shown that the catalytic ability of the calixarenes 85 and 86 was closely related to their remarkable hydrophobicity and their recognition abilities toward the reactants through hydrogen-bonding interactions with a thioureido group at the upper rim. The catalysts were more active using water as reaction medium than other organic solvents, the reaction was completely regioselective affording only the $\gamma$-adducts $\mathbf{8 3}$ and, interestingly, a switch of stereoselectivity was observed going from organic solvent to water with a preference for anti diastereoisomer 83. It is noteworthy that, by increasing the dimension of the calixarene-catalyst (85 vs. 86), and consequently its hydrophobicity, a significant increase of the reaction rate occurred. Binding studies between catalyst and $\alpha$-ketoesters by ${ }^{1} \mathrm{H}$-NMR spectroscopy and molecular mechanics calculations clearly indicated a supramolecular control of this catalysis associated with recognition abilities of calixarenes (De Rosa et al., 2016).

In a later paper, the same authors proposed that the hydrophobic amplification observed under "on- water" conditions could enable even weaker $\mathrm{H}$-bond donor moieties to catalyze the VMAR under "on-water" conditions (De Rosa et al., 2017b). In fact, simple tetraminocalix[4]arene 87 with weak $\mathrm{H}$-bond donor $\mathrm{NH}_{2}$ groups was an efficient organocatalyst for the reaction of TMSFO $\mathbf{8 2}$ and $\alpha$-ketoester $\mathbf{8 1}$ under "onwater" conditions and its catalytic activity was superior to that in organic solvents. Furthermore, its activity was better than previous catalysts $\mathbf{8 5}$ and $\mathbf{8 6}$ in terms both conversion, reaction times and selectivity and there was a switch of the stereoselectivity in favor of $s y n$-adduct (Figure 13). The reaction was general with a variety of $\alpha$-ketoesters with good to high yields and showed in all cases a preference for syn diastereomer syn 83. The reaction outcome was rationalized through a multipoint recognition model where the amino groups of the calixarene 

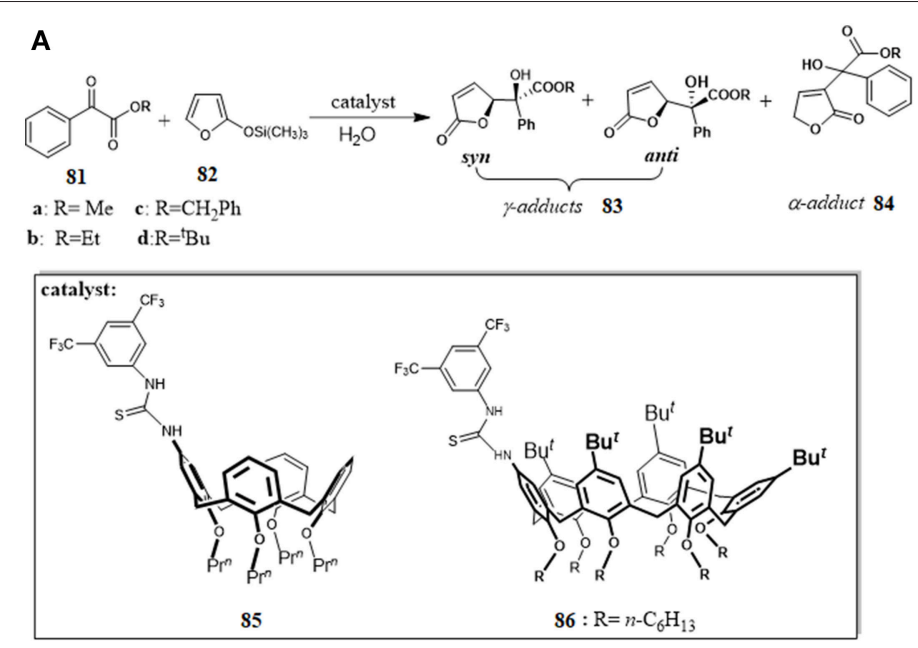

B
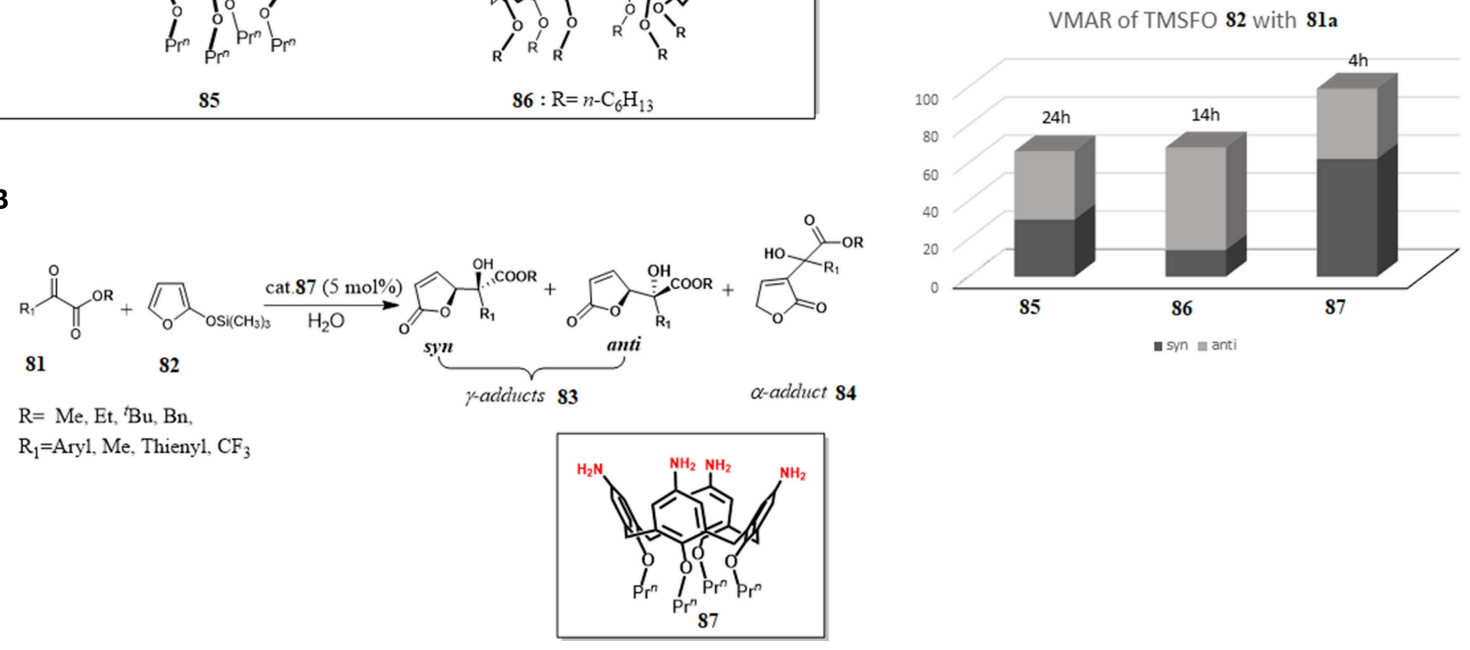

FIGURE 13 | Calixarenes as efficient organocatalyst for a vinylogous Mukaiyama aldol reaction (VMAR) under "on-water" conditions: (A) VMAR promoted by thioureido-calixarene derivatives 85 and 86; (B) VMAR catalyzed by tetraminocalix[4]arene 87.

were engaged in $\mathrm{H}$-bond interactions with both reactants favoring the stabilization of a ternary complex $\mathbf{8 1 . 8 2 . 8 7}$ that drove the attack at the activated carbonyl group of $\alpha$-ketoesters on a favored side. The proposed model was in agreement with the differences in the conversion and stereoselectivity detected with different substrates.

\section{CONCLUSION}

In the last years, significant advances have been made in the field of supramolecular organocatalysis using water as a reaction medium and thus demonstrating its synthetic potential. Different types of reactions promoted by supramolecular organocatalysts in water have been reported, thus providing not only environmentally friendly and efficient procedures, but in some cases new reactivity and reaction pathways different from those in organic solvents. Two principal topics drive this type of catalysis: (1) the hydrophobic effect and (2) the molecular recognition. Here, we have focused our attention on selected recent developments in this field using cyclodextrins and calixarenes as supramolecular scaffolds. These macrocycles are interesting because they provide a hydrophobic cavity, with tunable size and shape, capable of selectively accommodating the substrates isolating them from the reaction environment. In addition, the easy functionalization of their scaffold allows to introduce additional catalytic groups or binding sites in specific positions. The reported examples highlight how the combined action of these two characteristics have a positive effect on the reaction outcome.

In analogy to natural enzymes which have evolved over time improving efficiency and selectivity, we think that supramolecular organocatalysis in water can be expected to grow in the coming years demonstrating a further broadening of its applications.

\section{AUTHOR CONTRIBUTIONS}

MD: Wrote manuscript and chose references; PL: Gave assistance for literature search; CT: Provided assistance for some revisions; AS: Contributed to the discussions and gave assistance for literature search; CG: Designed the main content; PN: Provided professional advice. All authors read and approved the final manuscript version to be submitted. 


\section{REFERENCES}

Akelis, L., Rousseau, J., Juskenas, R., Dodonova, J., Rousseau, C., Menuel, S., et al. (2016). Greener Paal-Knorr pyrrole synthesis by mechanical activation. Eur. J. Org. Chem. 2016, 31-35. doi: 10.1002/ejoc.201501223

Aktas, M., Uyanik, A., Eymur, S., and Yilmaz, M. (2016). L-proline derivatives based on a calix[4]arene scaffold as chiral organocatalysts for the direct asymmetric aldol reaction in water. Supramol. Chem. 28, 351-359. doi: 10.1080/10610278.2015.1073288

Arduini, A., Orlandini, G., Secchi, A., Credi, A., Silvi, S., and Venturi, M. (2016). "Calixarene threading by viologen-based axles," in Calixarenes and Beyond, eds P. Neri, J. L. Sessler, and M.-X Wang (Cham: Springer International Publishing), 761-781.

Bai, C. C., Tian, B. R., Zhao, T., Huang, Q., and Wang, Z. Z. (2017). CyclodextrinCatalyzed organic synthesis: reactions, mechanisms, and applications. Molecules 22:E1475. doi: 10.3390/molecules22091475

Bogliotti, N., and Dalko, P. I. (2007). "Shape- and site-selective asymmetric reactions", in Enantioselective Organocatalysis: Reactions and Experimental Procedures, ed P. I. Dalko (Weinheim: Wiley-VCH Verlag GmbH \& Co. KGaA), 425-449.

Böhmer, V. (1995). Calixarenes, macrocycles with (Almost) unlimited possibilities. Angew. Chem. Int. Ed. Engl. 34, 713-745. doi: 10.1002/anie.199507131

Borsato, G., and Scarso, A. (2016). "Catalysis within the self-assembled resorcin[4]arene hexamer," in Organic Nanoreactors. From Molecular to Supramolecular Organic Compounds, ed S. Sadjadi (Boston, MA: Academic Press), 203-234.

Breslow, R. (1991). Hydrophobic effects on simple organic reactions in water. Acc. Chem. Res. 24, 159-164. doi: 10.1021/ar00006a001

Breslow, R., and Dong, S. D. (1998). Biomimetic reactions catalyzed by cyclodextrins and their derivatives. Chem. Rev. 98, 1997-2011.

Bugg, T. D. H. (2012). Introduction to Enzyme and Coenzyme Chemistry, 3rd Edn. Chichester: John Wiley \& Sons, Ltd

Butler, R. N., and Coyne, A. G. (2010). Water: nature's reaction enforcercomparative effects for organic synthesis "In-water" and "On-Water". Chem. Rev. 110, 6302-6337. doi: 10.1021/cr100162c

Cacciapaglia, R., and Mandolini, L. (2000). "Calixarene based catalytic system," in Calixarenes in Action, eds L. Mandolini and R. Ungaro (Singapore: Imperial College Press), 241-264.

Copeland, R. A. (2002). Enzymes: A Pratical Introduction to Structure, Mechanism, and Data Analysis, 2nd Edn. New York, NY: John Wiley \& Sons, Inc.

Deraedt, C., and Astruc, D. (2016). Supramolecular nanoreactors for catalysis. Coord. Chem. Rev. 324, 106-122. doi: 10.1016/j.ccr.2016.07.007

De Rosa, M., La Manna, P., Soriente, A., Gaeta, C., Talotta, C., Hickey, N., et al. (2017a). Supramolecular synthons in the gamma-hydroxybutenolides. Cryst. Eng. Comm. 19, 5079-5088. doi: 10.1039/C7CE00953D

De Rosa, M., La Manna, P., Soriente, A., Gaeta, C., Talotta, C., Hickey, N., et al. (2017b). A simple tetraminocalix[4]arene as a highly efficient catalyst under "On-Water" conditions through hydrophobic amplification of weak hydrogen bonds. Chem. Eur. J. 23, 7142-7151. doi: 10.1002/chem.201701247

De Rosa, M., La Manna, P., Soriente, A., Gaeta, C., Talotta, C., and Neri, P. (2016). Exploiting the hydrophobicity of calixarene macrocycles for catalysis under “on-water" conditions. RSC Adv. 6, 91846-91851. doi: 10.1039/C6RA19270J

De Rosa, M., Soriente, A., Concilio, G., Talotta, C., Gaeta, C., and Neri, P. (2015). Nucleophilic functionalization of the Calix[6]arene Para- and Meta-p position via p-Bromodienone route. J. Org. Chem. 80, 7295-7300. doi: 10.1021 /acs.joc.5b00978

De Rosa, M., Talotta, C., Gaeta, C., Soriente, A., Neri, P., Pappalardo, S., et al. (2017c). Calix[5] arene through-the-annulus threading of dialkylammonium guests weakly paired to the TFPB anion. J. Org. Chem. 82, 5162-5168. doi: 10.1021 /acs.joc.7b00406

De Rosa, M., Talotta, C., and Soriente, A. (2009). A new organocatalytic approach to substituted unsaturated lactams. Lett. Org. Chem. 6, 301-305. doi: $10.2174 / 157017809788489936$

Díaz- Moscoso, A., Arroyave, F. A., and Ballester, P. (2016). Moving systems of polar dimeric capsules out of thermal equilibrium by light irradiation. Chem. Comm. 52, 3046-3049. doi: 10.1039/C5CC10403C

Dong, Z., Luo, Q., and Liu, J. (2012). Artificial enzymes based on supramolecular scaffolds. Chem. Soc. Rev. 41, 7890-7908. doi: 10.1039/c2cs35207a
Dong, Z., Wang, Y., Yin, Y., and Liu, J. (2011). Supramolecular enzyme mimics by self-assembly. Curr. Opin. Colloid Interface Sci. 16, 451-458. doi: 10.1016/j.cocis.2011.08.006

Doyagüez, E. G., and Fernández-Mayoralas, A. (2012). Proline -cyclodextrin conjugates: synthesis and evaluation as catalysts for aldol reaction in water. Tetrahedron 68, 7345-7354. doi: 10.1016/j.tet.2012.06.089

Dzierzbicka, K., Trzonkowski, P., Sewerynek, P. L., and Mysliwski, A. (2003). Synthesis and cytotoxic activity of conjugates of muramyl and normuramyl dipeptides with batracylin derivatives. J. Med. Chem. 46, 978-986. doi: $10.1021 / \mathrm{jm} 021067 \mathrm{v}$

Eymur, S., Akceylan, E., Sahin, O., Uyanik, A., and Yilmaz, M. (2014). Direct enantioselective aldol reactions catalyzed by calix[4]arenebased L-proline derivatives in the water. Tetrahedron 70, 4471-4477. doi: 10.1016/j.tet.2014.05.034

Floresta, G., Talotta, C., Gaeta, C., De Rosa, M., Chiacchio, U., Neri, P., et al. (2017). $\gamma$-Cyclodextrin as a catalyst for the synthesis of 2methyl-3,5-diarylisoxazolidines in water. J. Org. Chem. 82, 4631-4639. doi: 10.1021 /acs.joc.7b00227

Gaeta, C., Martino, M., Gregoli, L., and Neri, P. (2002). Convenient regioselective functionalization at the upper-rim of p-tert-butylcalix[8]arene through a protection-deprotection procedure. Tetrahedron Lett. 43, 8875-8878. doi: 10.1016/S0040-4039(02)02204-9

Gaeta, C., Talotta, C., De Rosa, M., Soriente, A., and Neri, P. (2016). "Calixarene threading via superweak anion," in Calixarenes and Beyond, eds P. Neri, J. L. Sessler, and M.-X. Wang (Cham: Springer International Publishing), 783-809.

Gaeta, C., Talotta, C., Farina, F., Teixeira, F. A., Marcos, P. A., Ascenso, J. R., et al. (2012). Alkylammonium cation complexation into the narrow cavity of Dihomooxacalix[4]arene macrocycle. J. Org. Chem. 77, 10285-10293. doi: $10.1021 /$ jo3019945

Gaeta, C., Talotta, C., Mirra, S., Margarucci, L., Casapullo, A., and Neri, P. (2013). Catenation of calixarene annulus. Org. Lett. 15, 116-119. doi: $10.1021 / \mathrm{ol} 303142 \mathrm{c}$

Giacalone, F., and Gruttadauria, M. (2013). "Water in organocatalytic reactions," in Comprehensive Enantioselective Organocatalysis: Catalysts, Reactions, and Applications, ed P. I. Dalko (Weinheim: Wiley-VCH Verlag GmbH \& Co. KGaA), 673-717.

Guo, D.-S., and Liu, Y. (2014). Supramolecular chemistry of pSulfonatocalix[n]arenes and its biological applications. Acc. Chem. Res. 47, 1925-1934. doi: 10.1021/ar500009g

Guo, D.-S., Uzunova, V. D., Su, X., Liu, Y., and Nau, W. M. (2011). Operational calixarene-based fluorescent sensing systems for choline and acetylcholine and their application to enzymatic reactions. Chem. Sci. 2, 1722-1734. doi: 10.1039/C1SC00231G

Guo, D.-S., Wang, K., Wang, Y.-X., and Liu, Y. (2012). CholinesteraseResponsive supramolecular vesicle. J. Am. Chem. Soc. 134, 10244-10250. doi: $10.1021 / \mathrm{ja} 303280 \mathrm{r}$

Guo, D.-S., Yang, J., and Liu, Y. (2013). Specifically monitoring butyrylcholinesterase by supramolecular tandem assay. Chem. Eur. J. 19, 8755-8759. doi: 10.1002/chem.201300980

Gutache, C. D., Kung, T. C., and Hsu, M-L. (1975). Abstracts of the 11th Midwest Regional Meeting of the American Chemical Society, Carbondale, IL.

Gutsche, C. D., and Muthukrishnan, R. (1978). Calixarenes. 1. analysis of the product mixtures produced by the base-catalyzed condensation of formaldehyde with para-substituted phenols. J. Org. Chem. 43, 4905-4906. doi: $10.1021 /$ jo00419a052

Hapiot, F., Bricout, H., Menuel, S., Tilloy, S., and Monflier, E. (2014). Recent breakthroughs in aqueous cyclodextrin-assisted supramolecular catalysis. Catal. Sci. Technol. 4, 1899-1908. doi: 10.1039/c4cy00005f

Hapiot, F., Menuel, S., Ferreira, M., Léger, B., Bricout, H., Tilloy, S., et al. (2017). Catalysis in cyclodextrin-Based unconventional reaction media: recent developments and future opportunities. ACS Sustainable Chem. Eng. 5, 3598-3606. doi: 10.1021/acssuschemeng.6b02886

Hattori, K., and Ikeda, H. (2006). "Modification of cyclodextrins and the chemistry of modified cyclodextrins," in Cyclodextrins and Their Complexes, ed $\mathrm{H}$. Dodziuk (Weinheim: Wiley-VCH Verlag GmbH \& Co. KGaA), 31-64.

Inoue, Y., Hakushi, T., Liu, Y., Tong, L., Shen, B., and Jin, D. (1993).Thermodynamics of molecular recognition by cyclodextrins. 1. calorimetric titration of inclusion complexation of naphthalenesulfonates 
with.alpha.-,.beta.-, and gamma.-cyclodextrins: enthalpy-entropy compensation. J. Am. Chem. Soc. 115, 475-481. doi: 10.1021/ja00055a017

Jimeno, C. (2016). Water in asymmetric organocatalytic systems: a global perspective. Org. Biomol. Chem. 14, 6147-6164. doi: 10.1039/C6OB00783J

Kanagaraj, K., and Pitchumani, K. (2013). Per-6-amino- $\beta$-cyclodextrin as a chiral base catalyst promoting one-pot asymmetric synthesis of 2-Aryl-2,3-dihydro4-quinolones. J. Org. Chem. 78, 744-751. doi: 10.1021/jo302173a

Kirby, A. J., and Hollfelder, F. (2010). From Enzyme Models to Model Enzymes. Cambridge: John Wiley \& Sons, Ltd.

Kleiner, C. M., and Schreiner, P. R. (2006). Hydrophobic amplification of noncovalent organocatalysis. Chem. Comm. 4315-4317. doi: 10.1039/b605850g

Kobayashi, S., and Li, C. -J. (2012). Science of Synthesis: Water in Organic Synthesis, eds S. Kobayashi, E. M. Carreira, C. P. Decicco, A. Fürstner, G. A. Molander, (Stuttgart: Thieme).

Komiyama, M., and Monflier, E. (2006). "Cyclodextrin catalysis," in Cyclodextrin and Their Complexes, ed H. Dodziuk (Weinheim: Wiley-VCH Verlag GmbH \& Co. KGaA), 93-105.

Konkala, K., Chorasia, R., Manjari, P. S., Domingues, N. L. C., and Katla, R. (2016). B-Cyclodextrin as a recyclable catalyst: aqueous phase one-pot four component synthesis of polyfunctionalized pyrroles. RSC Adv. 6, 43339-43344. doi: 10.1039/C6RA08335H

Kshirsagar, U. A. (2015). Recent developments in the chemistry of quinazolinone alkaloids. Org. Biomol. Chem. 13, 9336-9352. doi: 10.1039/C5OB01379H

Kuah, E., Toh, S., Yee, J., Ma, Q., and Gao, Z. (2016). Enzyme mimics: advances and applications. Chem. Eur. J. 22, 8404-8430. doi: 10.1002/chem.201504394

Kumar, A., and Shukla, R. D. (2014). $\beta$-Cyclodextrin catalysed C-C bond formation via $\mathrm{C}\left(\mathrm{sp}^{3}\right)$ - $\mathrm{H}$ functionalization of 2-Methyl azaarenes with diones in aqueous medium. Green Chem. 17, 848-851. doi: 10.1039/C4GC02287D

Kumar, A., Tripathi, V. D., and Kumar, P. (2011). $\beta$-Cyclodextrin catalysed synthesis of tryptanthrin in water. Green Chem. 13, 51-54. doi: 10.1039/C0GC00523A

Kumar, S., and Ahmed, N. (2016). $\beta$-Cyclodextrin/IBX in water: highly facile biomimetic one pot deprotection of THP/MOM/Ac/Ts ethers and concomitant oxidative cleavage of chalcone epoxides and oxidative dehydrogenation of alcohols. Green Chem. 18, 648-656. doi: 10.1039/C5GC01785H

Kumar, S., Verma, N., and Ahmed, N. (2015). $\beta$-Cyclodextrin in water: highly facile biomimetic one pot deprotection of phenolic THP/MOM/Ac/Ts ethers and concomitant regioselective cyclization of chalcone epoxides and 2'aminochalcones. RSC Adv. 5, 85128-85138. doi: 10.1039/C5RA15996B

La Manna, P., De Rosa, M., Talotta, C., Gaeta, C., Soriente, A., Floresta, G., et al. (2018). The hexameric resorcinarene capsule as an artificial enzyme: ruling the regio and stereochemistry of a 1,3-dipolar cycloaddition between nitrones and unsaturated aldehydes. Org. Chem. Front. 5, 827-837. doi: 10.1039/C7QO00942A

La Manna, P., Talotta, C., Gaeta, C., Soriente, A., De Rosa, M., and Neri, P. (2017). Threading of an inherently directional calixarene wheel with oriented ammonium axles. J. Org. Chem. 82, 8973-8983. doi: 10.1021/acs.joc.7b01388

La Sorella, G., Strukul, G., and Scarso, A. (2015). Recent advances in catalysis in micellar media. Green Chem. 17, 644-683. doi: 10.1039/C4GC01368A

Li, Z.-Y., Chen, J.-W., Liu, Y., Xia, W., and Wang, L. (2011). The use of calixarenes in asymmetric catalysis. Curr. Org. Chem. 15, 39-61. doi: $10.2174 / 138527211793797837$

Li, Z.-Y., Chen, J.-W., Wang, L., and Pan, Y. (2009). Highly enantioselective direct aldol reactions catalyzed by proline derivatives based on a calix[4] arene Scaffold in the presence of water. SynLett. 14, 2356-2360. doi: 10.1055/s-0029-1217710

Li, Z.-Y., Chen, J.-W., Zheng, C.-Q., Yin, Y., Wang, L., and Sun, X.-Q. (2017). Highly enantioselective aldol reactions catalysed by reusable upper rim-functionalized calix[4] arene-based L-proline organocatalyst in aqueous conditions. Tetrahedron 73, 78-85. doi: 10.1016/j.tet.2016.11.052

Li, Z.-Y., Lu, C.-X., Huang, G., Ma, J.-J., Sun, H., Wang, L., et al. (2010). Novel prolinamide organocatalysts based on calix[4]arene Scaffold for the enantioselective direct aldol reaction. Lett. Org. Chem. 7, 461-466. doi: $10.2174 / 157017810791824919$

Liu, K., and Zhang, G. (2015). Direct asymmetric aldol reactions in aqueous media catalysed by a $\beta$-cyclodextrin-proline conjugate with a urea linker. Tetrahedron Lett. 56, 243-246. doi: 10.1016/j.tetlet.2014.11.084

Longstreet, A. R., and McQuade, D. T. (2013). Organic reaction systems: using microcapsules and microreactors to perform chemical synthesis. Acc. Chem. Res. 46, 327-338. doi: 10.1021/ar300144x
Macaev, F., and Boldescu, V. (2015). Cyclodextrins in asymmetric and stereospecific synthesis. Symmetry 7, 1699-1720. doi: 10.3390/sym7041699

Marchetti, L., and Levine, M. (2011). Biomimetic catalysis. ACS Catal. 1, 1090-1118. doi: 10.1021/cs200171u

Marinescu, L., and Bols, M. (2010). Cyclodextrins as supramolecular organocatalysts. Curr. Org. Chem. 14, 1380-1398. doi: 10.2174/138527210791616885

Martinez-Viturro, C. M., and Dominguez, D. (2007). Synthesis of the antitumoural agent batracylin and related isoindolo[1,2-b]quinazolin-12(10H)-ones. Tetrahedron Lett. 48, 1023-1026. doi: 10.1016/j.tetlet.2006.11.168

Mase, N., and Barbas, C. F. III. (2010). In water, on water, and by water: mimicking nature's aldolases with organocatalysis and water. Org. Biomol. Chem. 8, 4043-4050. doi: 10.1039/C004970K

Menuel, S., Rousseau, J., Rousseau, C., Vaičiunaite, Dodonova, J., Tumkevičius, S., and Monflier, E. (2014). Access to pyrrole derivatives in water with the assistance of methylated cyclodextrins. Eur. J. Org. Chem. 2014, 4356-4361. doi: 10.1002/ejoc.201402327

Narayan, S., Muldoon, J., Finn, M. G., Fokin, V. V., Kolb, H. C., and Sharpless, K. B. (2005). "On-water": unique reactivity of organic compounds in aqueous suspension. Angew. Chem. Int. Ed. 44, 3275-3279. doi: 10.1002/anie.200462883

Neri, P., Sessler, J. L., and Wang, M.-X. (2016). Calixarenes and Beyond. Cham: Springer International Publishing.

Pirrung, M. C. (2006). Acceleration of organic reactions through aqueous solvent effects. Chem. Eur. J. 12, 1312-1317. doi: 10.1002/chem.200500959

Pirrung, M. C., and Sarma, K. D. (2004). Multicomponent reactions are accelerated in water. J. Am. Chem. Soc. 126, 444-445. doi: 10.1021/ja038583a

Rahaman, M., Ling, I., Abdullah, N., Hashim, R., and Hajra, A. (2015). Organocatalysis by p-sulfonic acid calix[4]arene: a convenient and efficient route to 2,3-dihydroquinazolin-4(1H)-ones in water. $R S C A d v .5,7755-7760$. doi: 10.1039/C4RA16374E

Raj, M., and Singh, V. K. (2009). Organocatalytic reactions in water. Chem. Commun. 6687-6703. doi: 10.1039/b910861k

Ramesh, K., Karnakar, K., Satish, G., Harsha Vardhan Reddy, K., and Nageswar, Y. V. D. (2012). Tandem supramolecular synthesis of substituted 2-aryl-2,3dihydroquinazolin- $4(1 \mathrm{H})$-ones in the presence of $\beta$-cyclodextrin in water. Tetrahedron Lett. 53, 6095-6099. doi: 10.1016/j.tetlet.2012.08.141

Raynal, M., Ballester, P., Vidal-Ferran, A., and van Leeuwen, P. W., (2014). Supramolecular catalysis. Part 2: artificial enzyme mimics. Chem. Soc. Rev. 43, 1734-1785. doi: 10.1039/C3CS60037H

Rebek, J. Jr. (2000). Host-guest chemistry of calixarene capsules. Chem. Commun. 637-643. doi: 10.1039/a910339m

Rideout, D. C., and Breslow, R. (1980). Hydrophobic acceleration of diels-alder reactions. J. Am. Chem. Soc. 102, 7816-7817. doi: 10.1021/ja00546a048

Rudkevic, D. M. (2001). “ Self-assembly in solution," in Calixarenes 2001, eds Z. Asfari, V. Bohmer, J. Harrowfield, and J. Vicens (Dordrecht: Kluwer), 155-180.

Rueping, M., and Theissmann, T. (2010). Asymmetric brønsted acid catalysis in aqueous solution. Chem. Sci. 1, 473-476. doi: 10.1039/c0sc00206b

Sahin, O., Eymur, S., Uyanik, A., Akceyla, E., and Yilmaz, M. (2016). Chiral calix[4]arenes-bearing prolinamide functionality as organocatalyst for asymmetric direct aldol reactions in water. Polycyclic Aromatic Compounds 38, 1-12. doi: 10.1080/10406638.2016.1176058

Sakthivel, K., Notz, W., Bui, T., and Barbas, C. F. (2001). Amino acid catalyzed direct asymmetric aldol reactions: a bioorganic approach to catalytic asymmetric carbon-carbon bond-forming reactions. J. Am. Chem. Soc. 123, 5260-5267. doi: 10.1021/ja010037z

Sayin, S., and Yilmaz, M. (2014). The synthesis of new calix[n]arene quaternary ammonium salts and investigation of their catalytic affinities for three component Mannich-type reactions in water. RSC Adv. 4, 2219-2225. doi: 10.1039/C3RA43881C

Simon, M.-O., and Li, C.-J. (2012). Green chemistry oriented organic synthesis in water. Chem. Soc. Rev. 41, 1415-1427. doi: 10.1039/C1CS15222J

Srivastava, M., Rai, P., Singh, J., Yadav, S., Tripathi, B. P., and Singh, J. (2016). Role of $\beta$-CD in water as supramolecular catalysis. Curr. Organocatalysis 3, 32-38. doi: $10.2174 / 2213337202666150709164207$

Steed, J. W., and Atwood, J. L. (2009). "Biological mimics and supramolecular catalysis," in Supramolecular Chemistry, 2nd Edn. ed. Wiley (Chichester: John Wiley \& Sons, Ltd), 778-827.

Stoikov, I. I., Yakimova, L. S., Puplampu, J. B., and Vavilova, A. A. (2016). "System based on calixarenes as the basis for the creation of catalysts and nanocontainers," in Organic Nanoreactor. From Molecular to Supramolecular 
Organic Compounds, ed S. Sadjadi (Boston, MA: Academic Press), 85-110.

Sun, Y., Mei, Y., Quan, J., Xiao, X., Zhang, L., Tian, D., et al. (2016). The macroscopic wettable surface: fabricated by calix[4] arene-based hostguest interaction and chiral discrimination of glucose. Chem. Comm. 52, 14416-14418. doi: 10.1039/C6CC07956C

Takahashi, K. (1998). Organic reactions mediated by cyclodextrins. Chem. Rev. 98, 2013-2033.

Talotta, C., Caruso, T., De Rosa, M., Gaeta, C., Soriente, A., and Neri, P. (2018). Threading fluorescent calixarene-wheels with ammonium axles. Supramol. Chem. 30, 1-15. doi: 10.1080/10610278.2018.1424852

Talotta, C., Gaeta, C., De Rosa, M., Ascenso, J. R., Marcos, P. M., and Neri, P. (2016). Alkylammonium guest induced-fit recognition by a flexible dihomooxacalix[4]arene derivative. Eur. J. Org. Chem. 2016, 158-167. doi: 10.1002/ejoc.201501319

Talotta, C., Gaeta, C., De Rosa, M., Soriente, A., and Neri, P. (2017). “Calixarenes," in Comprehensive Supramolecular Chemistry, II., 2nd Edn, eds W. G. Gokel, L. Barbour, J. L. Atwood (The Boulevard, Langford Lane, Kidlington Oxford, UK: Elsevier), 49-74.

Tayade, Y. A., Patil, D. R., Wagh, Y. B., Jangle, A. D., and Dalal, D. S. (2015). An efficient synthesis of 3-indolyl-3-hydroxy oxindoles and 3,3-di(indolyl)indolin2 -ones catalyzed by sulfonated $\beta-\mathrm{CD}$ as a supramolecular catalyst in water. Tetrahedron Lett. 56, 666-673. doi: 10.1016/j.tetlet.2014.12.012

Uyanik, A., Bayrakci, M., Eymur, S., and Yilmaz, M. (2014). Upper rimfunctionalized calix[4]arene-based l-proline as organocatalyst for direct asymmetric aldol reactions in water and organic media. Tetrahedron 70, 9307-9313. doi: 10.1016/j.tet.2014.10.063

Van Etten, R., Clowes, G. A., Sebastian, J.:F., and Bender, M. L. (1967a). The mechanism of the cycloamylose-accelerated cleavage of phenyl ester. J. Am. Chem. Soc. 89, 3253. doi: 10.1021/ja00989a028

Van Etten, R., Sebastian, J.:F., Clowes, G. A., and Bender, M. L. (1967b). Acceleration of phenyl ester cleavage by cycloamyloses. A model for enzymatic specificity. J. Am. Chem. Soc. 89, 3242. doi: 10.1021/ja00989a027

Xie, Y., Mao, L., and Li, L. (2013). Calix[6]arene sulfonic acids catalysed Michael reactions of indoles with $\alpha, \beta$-unsaturated ketones in water assisted by microwave radiation. J. Chem. Res. 37, 476-479. doi: 10.3184/174751913X13734725288804

Yang, F., Guo, H., and Jiao, Z. (2012). Calixarene ionic liquids: excellent phase transfer catalysts for nucleophilic substitution reaction in water. J. Iran. Chem. Soc. 9, 327-332. doi: 10.1007/s13738-011-0027-6

Yeon, Y., Leem, S., Wagen, C., Lynch, V. M., Kim, S. K., and Sessler, J. L. (2016). 3-(Dicyanomethylidene)indan-1-one-Functionalized Calix[4]areneCalix[4]pyrrole hybrid: an ion-pair sensor for cesium salts. Org. Lett. 18, 4396-4399. doi: 10.1021/acs.orglett.6b02155

Yilmaz, M., and Sayin, S. (2016). "Calixarenes in organo and biomimetic catalysis," in Calixarenes and Beyond, eds P. Neri, J. L. Sessler, and M. X. Wang (Cham: Springer International Publishing),719-742.

Zhang, Q., Catti, L., Pleiss, J., and Tiefenbacher, K. (2017). Terpene cyclizations inside a supramolecular catalyst: leaving-group-controlled product selectivity and mechanistic studies. J. Am. Chem. Soc. 139, 11482-11492. doi: 10.1021/jacs.7b04480

Zhang, Q., and Tiefenbacher, K. (2015). Terpene cyclization catalysed inside a self-assembled cavity. Nat. Chem. 7, 197-202. doi: 10.1038/ nchem. 2181

Zheng, Z., Geng, W.-C.-, Gao, J., Wang, Y.-Y., Sun, H., and Guo, D.-S. (2018). Ultrasensitive and specific fluorescence detection of a cancer biomarker via nanomolar binding to a guanidinium-modified calixarene. Chem. Sci. 9, 2087-2091. doi: 10.1039/C7SC04989G

Conflict of Interest Statement: The authors declare that the research was conducted in the absence of any commercial or financial relationships that could be construed as a potential conflict of interest.

Copyright (C) 2018 De Rosa, La Manna, Talotta, Soriente, Gaeta and Neri. This is an open-access article distributed under the terms of the Creative Commons Attribution License (CC BY). The use, distribution or reproduction in other forums is permitted, provided the original author(s) and the copyright owner are credited and that the original publication in this journal is cited, in accordance with accepted academic practice. No use, distribution or reproduction is permitted which does not comply with these terms. 